Florida International University FIU Digital Commons

\title{
Stress and Coping Style: An Extension to the Transactional Cognitive-Appraisal Model
}

Kerry A. Newness

Florida International University, knewn001@fiu.edu

DOI: $10.25148 /$ etd.FI1 1041507

Follow this and additional works at: https://digitalcommons.fiu.edu/etd

Part of the Psychology Commons

\section{Recommended Citation}

Newness, Kerry A., "Stress and Coping Style: An Extension to the Transactional Cognitive-Appraisal Model" (2011). FIU Electronic Theses and Dissertations. 346.

https://digitalcommons.fiu.edu/etd/346

This work is brought to you for free and open access by the University Graduate School at FIU Digital Commons. It has been accepted for inclusion in FIU Electronic Theses and Dissertations by an authorized administrator of FIU Digital Commons. For more information, please contact dcc@fiu.edu. 


\section{FLORIDA INTERNATIONAL UNIVERSITY}

Miami, Florida

\section{STRESS AND COPING STYLE: AN EXTENSION TO THE TRANSACTIONAL COGNITIVE-APPRAISAL MODEL}

A thesis submitted in partial fulfillment of the

requirements for the degree of

MASTER OF SCIENCE

in

PSYCHOLOGY

by

Kerry Ann Newness

2011 
To: Dean Kenneth Furton

College of Arts and Sciences

This thesis, written by Kerry Ann Newness, and entitled Stress and Coping Style: An Extension to the Transactional Cognitive-Appraisal Model, having been approved in respect to style and intellectual content, is referred to you for judgment.

We have read this thesis and recommend that it be approved.

$\begin{array}{r}\hline \text { Victoria Pace } \\ \hline \text { Chocklingam Viswesvaran } \\ \hline \text { Jesse S. Michel, Major Professor }\end{array}$

Date of Defense: January 26, 2011

The thesis of Kerry Ann Newness is approved.

Dean Kenneth Furton
College of Arts and Sciences

Interim Dean Kevin O'Shea

University Graduate School

Florida International University, 2011 


\section{DEDICATION}

I dedicate this work to my family who has instilled in me a passion to learn, especially to my mom who has provided continuous encouragement along the way. 


\section{ACKNOWLEDGMENTS}

I want to thank the professors represented on my committee for supporting me in my research endeavors and for facilitating my academic progress. Their guidance and expertise have certainly been an important factor in the developmental process, data collection, and analysis. I would also like to thank my colleagues who were encouraging and who provided motivation to complete the research and data collection used in my thesis. Lastly, I would like to thank authors Boyd, Lewin, and Sager for providing me with access to their in press research results. 


\title{
ABSTRACT OF THE THESIS \\ STRESS AND COPING STYLE: AN EXTENSION TO THE TRANSACTIONAL COGNITIVE-APPRAISAL MODEL
}

\author{
by \\ Kerry Ann Newness \\ Florida International University, 2011 \\ Miami, Florida \\ Professor Jesse S. Michel, Major Professor
}

The purpose of the current research was to integrate multiple theories of stress appraisals and to empirically test two separate transactional cognitive-appraisal models. It was predicted that the core self-evaluation personality characteristics and motivation orientation would moderate the relationship between challenge and hindrance stressors and coping style. Furthermore, it was predicted that coping would buffer the adverse effects of stress on domain performance and satisfaction. A series of multiple regression analyses were conducted to investigate the predicted moderators. Results suggest that core self-evaluations moderate the relationship between challenge stress and problemfocused coping as predicted in the challenge model but not for the hindrance stress model. Coping style did not significantly buffer the negative effects of stress on performance or satisfaction. Overall, the results provide partial support for the challengehindrance framework within the transactional appraisal model of stress. 


\section{TABLE OF CONTENTS}

CHAPTER

PAGE



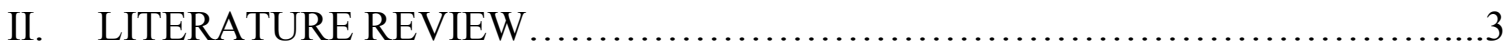



Cognitive Appraisal Process ..............................................6

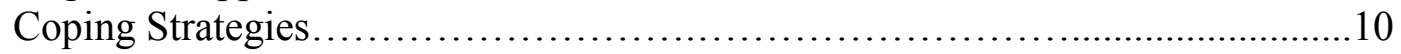

Core Self-Evaluations and Coping.............................................12

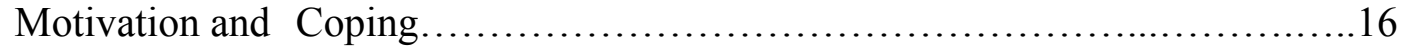

Coping and Performance.....................................................

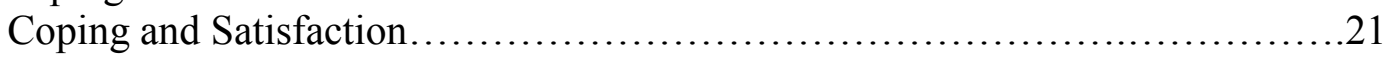

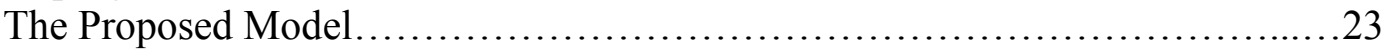

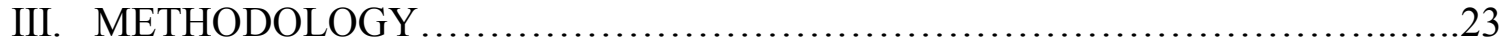

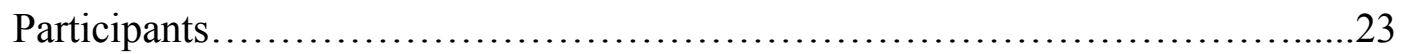

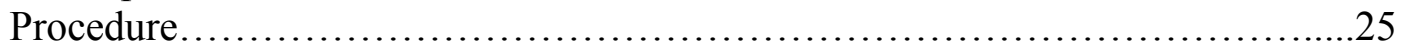

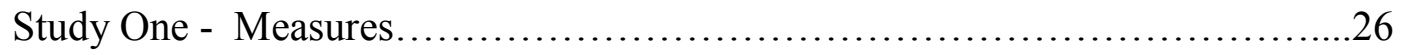

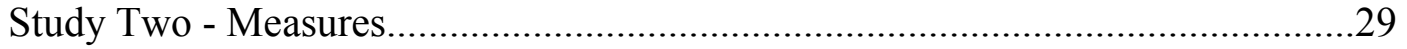

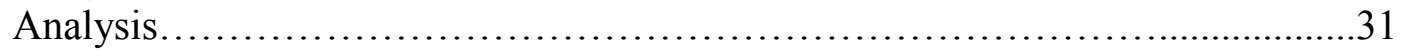





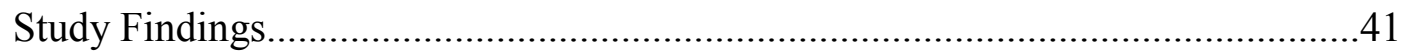

Theoretical and Practical Implications..................................................................57

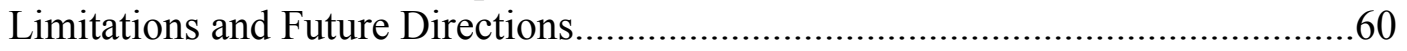

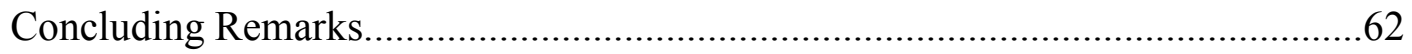

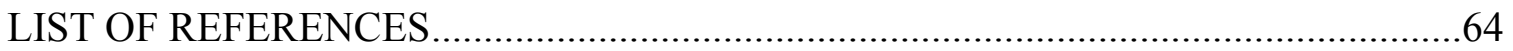






\section{LIST OF TABLES}

TABLE

PAGE

1. Correlations, Means, Standard Deviations, and Reliabilities for Students..................70

2. Moderated Regression for CSE, Challenge Stress, and Coping ................................71

3. Moderated Regression for CSE, Hindrance Stress, and Coping.....................72

4. Moderated Regression for Extrinsic Motivation Challenge Stress, and Coping........73

5. Moderated Regression for Extrinsic Motivation, Hindrance Stress, and Coping..........74

6. Moderated Regression for Intrinsic Motivation, Challenge Stress, and Coping...........75

7. Moderated Regression for Intrinsic Motivation, Hindrance Stress, and Coping........76

8. Moderated Regression for Problem-Focused Coping, Challenge, and Performance...77

9. Moderated Regression for Problem-Focused Coping, Hindrance, and Performance...78

10. Moderated Regression for Emotion-Focused Coping, Challenge, and Performance..79

11. Moderated Regression for Emotion-Focused Coping, Hindrance, and Performance..80

12. Moderated Regression for Maladaptive Coping, Challenge, and Performance........81

13. Moderated Regression for Maladaptive Coping, Hindrance, and Performance........82

14. Moderated Regression for Stressors, Problem-Focused Coping, and Satisfaction.....83

15. Moderated Regression for Stressors, Emotion-Focused Coping, and Satisfaction....84

16. Moderated Regression for Stressors, Maladaptive Coping, and Satisfaction.........85

17. Moderated Regression for CSE Self-Esteem, Stressors, and Coping................86

18. Moderated Regression for CSE Neuroticism, Stressors, and Coping................87

19. Moderated Regression for CSE Self-Efficacy, Stressors, and Coping..............88

20. Moderated Regression for CSE Locus of Control, Stressors, and Coping............89

21. Correlations, Means, Standard Deviations, and Reliabilities for Employees.........90 


\section{LIST OF FIGURES}

FIGURE

PAGE

1. Challenge Transactional Model of Stress............................................................ 91

2. Hindrance Transactional Model of Stress................................................................92

3. Interaction of Challenge Stress, Problem-Focused Coping, and CSE........................93

4. Interaction of Hindrance Stress, Problem-Focused Coping, and CSE.......................94

5. Interaction of Challenge Stress, Problem-Focused Coping, and Self-Esteem.............95

6. Interaction of Challenge Stress, Problem-Focused Coping, and Neuroticism.............96

7. Interaction of Challenge Stress, Problem-Focused Coping and Self-Efficacy............97

8. Interaction of Challenge Stress, Problem-Focused Coping and Locus of Control.......98

9. Interaction of Hindrance Stress, Problem-Focused Coping and Self-Esteem.............99

10. Interaction of Hindrance Stress, Problem-Focused Coping and Neuroticism...........100

11. Interaction of Hindrance Stress, Problem-Focused Coping, and Self-Efficacy.........101

12. Interaction of Hindrance Stress, Problem-Focused Coping and Locus of Control....102 


\section{CHAPTER I - INTRODUCTION}

The United States (U.S.) workforce has undergone significant changes over the past several decades; employees experience increased job demands, broader job scopes, situational restraints at work, and role ambiguity which has resulted in increased work stress (Jex, 1998; Podsakoff, LePine, \& LePine, 2007). There have been numerous explanations for the origin of these changes which include a decrease in the level of management control and a stronger emphasis being placed on innovation (Brunner \& Colarelli, 2004). With the high prevalence of stress experienced in the workplace, researchers need to focus on the antecedents and outcomes of this stress. From an applied perspective, the experience of work stress has been associated with negative organizational outcomes such as turnover intentions, actual turnover, reduced commitment, and reduced job satisfaction (Podsakoff, et al., 2007; Sonnentag, \& Frese, 2003; Welbourne, Eggerth, Hartley, Andrew, \& Sanchez, 2007). Over the past two to three decades numerous stress theories have emerged from social, cognitive, clinical and personality psychology subdivisions; however, researching stress in Industrial Organizational (IO) psychology has only recently gained support. In a theoretical piece discussing the direction of stress research and coping behavior, Schaubroeck (1999) proposed three essential directions for future research: 1) less attention should be placed on objective elements of work stress, 2) studying coping behaviors in IO/HR is an appropriate and promising outcome to examine, and 3) mental processes should be a

primary focus for this area of research. Since this proposal and call for further research in work stress, researchers have adopted and utilized extant stress theory to investigate contributing factors and outcomes of self-reported work stress. Despite the recent 
empirical findings within the work stress literature, the scope of these studies has been somewhat limited and further research is still necessary.

In the current study, the cognitive appraisal model of stressors (Lazarus \& Folkman, 1984) was adopted because its theoretical foundation suggests that specific types of situations result in positive and negative perceptions. For example, on the basis of the nature of some stressors, individuals appraise them as positive or negative because of the potential reward or threat. Therefore, two transactional models were developed for the current study: a challenge (i.e., stressors that have potential positive outcomes) model and a hindrance (i.e., stressors that have no potential positive outcomes) model. In addition to simply perceiving a stressor as a challenge or hindrance, theory suggests that individuals' coping strategies differ based on the stressor type (Pearsall, Ellis, \& Stein, 2009). Expanding upon the hypotheses of Lazarus and Folkman (1984), the proposed models were designed to examine individual differences that may moderate the adverse organizational outcomes of persistent stressors. Until recently researchers have recognized the significance of the lens through which an individual views a stressor. In fact, empirical evidence suggests that individuals with a positive self-evaluation actually appraise fewer negative stressors (Kammeyer-Mueller, \& Judge, 2009). The current study assessed core self-evaluations and motivation orientation as two possible moderators of the relationship between stressors and coping styles. However, the primary aim of the current study was to develop a comprehensive model to integrate all of these theoretical linkages: challenge-hindrance stressors, personality, and cognitive moderators of the stress-coping appraisal process. 


\section{CHAPTER II - LITERATURE REVIEW}

Work Stress

The foundation of the proposed transactional models is that of stress. Early conceptualizations of work stress suggested that an inverted U-shaped relationship existed between the amount of reported stress and performance (Selye, 1982). Intuitively, this conceptualization of stress has some validity; however, simply examining stress on a single continuum could not adequately explain why some individuals were more predisposed to stress than others and why some individuals were more tolerant of particular stressors. An extension of this theory categorized stress in terms of eustress and distress based on amount; however, there has been recent support for a distinction based on type of stressor instead of amount of stress (Lazarus \& Folkman, 1984). Lazarus and Folkman (1984) proposed a transactional stress model, in which individuals cognitively appraise an event to determine the extent to which that event has the potential to deplete their resources. One benefit to this stress theory was that it accommodated for individual differences in appraisal, while the single continuum theory did not. In keeping with this transactional model, stress will be defined as the psychological response to a situation or stimuli whereby an individual appraises the situation or stressor as exceeding their capabilities or resources. The stressors appraised as having the potential for personal growth, the attainment of goals, or rewards will be categorized as "challenges"; whereas, stressors appraised as having no potential personal gains will be categorized as "hindrances" (Selye, 1982). With regard to the categorization of work-related stressors, Cavanaugh, Boswell, Roehling, and Boudreau (2000) found that job overload, time pressures, and level of responsibility would be appraised as challenges and organizational 
politics, red tape, and job insecurity would be appraised as hindrances. LePine, LePine, and Jackson (2004) categorized school-related stressors on the basis of critical incidences; however, similar situations emerged as challenge and hindrance stressors in an academic setting. Ambiguity of work, hassles, and teacher favoritism were identified as hindrance stressors, while amount of work and time pressures were considered challenge stressors. As can be inferred, the transactional theory of stress seeks to explain the universality of stressor appraisals as either "challenging" or "hindrance" which is related to cognition, but an important extension to this model should include personality and individual difference variables.

The measurement of stress prior to the transactional stress model traditionally involved a self-report perceived stress scale, which did not differentiate between types of stressors. Assessing stress as a single continuum rather than distinguishing between eustress and distress in scales was found to actually diminish the otherwise significant effects (Cavanaugh, Boswell, Roehling, \& Boudreau, 2000). In fact, the main objective of Cavanaugh and colleagues (2000) was to establish a distinct relationship between challenge and hindrance stressors and to validate the use of a new scale to measure these constructs. Cavanaugh, et al. (2000) used several psychometric techniques to provide adequate content validation using judges, confirmatory factor analysis, and a correlational analysis of stress measures and outcome variables. Since the validation of the challenge and hindrance stress subscales, researchers have begun investigating the antecedents and outcomes of work stress in relation to the type of stressor.

Utilizing the challenge and hindrance framework, LePine, LePine, and Jackson (2004) investigated the possibility that some stressors might be positively related to 
learning while others might be negatively related to learning performance in a training situation. LePine and colleagues predicted that the relationship between exhaustion and stressor would be significant and positive regardless of the type of stressor (i.e., challenge or hindrance). The appraised stressor was also predicted to influence motivation to achieve; such that, a hindering situation would be related to decreased motivation and a challenging situation would increase motivation. LePine et al. (2004) suggested that the confirmation of the aforementioned hypotheses regarding learning performance could explain the inconsistencies found in extant literature with respect to stress and performance in the workplace. Specifically, the existing literature found that participants would experience increased performance with increased stress, but that relationship was only valid upon reaching a certain stress threshold; any additional stress would result in a decrease in performance. One of the major contributions of this study was that it provided an initial analysis of the challenge-hindrance stressor model and organizational outcomes of those distinct types of stressors. Interestingly, the model proposed by LePine et al. (2004) conceptualizes motivation to achieve as an outcome of the stress appraisal process. In a follow-up study of challenge and hindrance stressors and performance outcomes, LePine, Podsakoff, and LePine (2005) conducted a meta-analysis in which they had similar hypotheses. The aggregated meta-analytic data offered additional support for the relationship between the challenge-hindrance stressors and emotional exhaustion.

Podsakoff et al. (2007) conducted a meta-analysis specifically examining the organizational outcome variables as they relate to the challenge-hindrance stressor framework. Results suggested that both challenge and hindrance were related to the 
experience of strain, as was expected in their hypotheses. Hindrance stressors were strongly correlated with job satisfaction and commitment in the negative direction and challenge stressors with these outcomes in the positive direction. Both turnover intentions and actual turnover were related to challenge and hindrance in the negative and positive directions, respectively. Interestingly, Podsakoff et al. (2007) found stronger correlations for hindrance stressors than for challenge stressors. Perhaps negative situations were more salient for the employees in the studies coded for this meta-analysis. Another possible explanation for stronger hindrance correlations is that a challenge stressor combined with hindrance stressors could result in the compounding of negative perceptions. Given the number of organizational outcomes that are affected by employee stress, it is essential to develop a more comprehensive model using the challengehindrance framework and the possible moderators in the appraisal processes of stress. Furthermore, investigating the variance explained with two separate models (i.e. challenge model and hindrance model) could provide an explanation of the cognitive processing of the types of stressor. Workplace stress models using this framework have provided evidence to suggest the type of stress also influences organizational outcomes such that hindrance stressors produce higher rates of turnover and lower self-reported job satisfaction than challenge stressors.

Cognitive Appraisal Process

Lazarus and Folkman (1984) suggest that there is a series of cognitive appraisals that individuals make with regard to stressors: 1) Will this situation or stimuli deplete my capabilities or resources, 2) will the stimuli have the potential for personal benefit or not, and 3) how might I best cope with this situation or stimuli? Cognitive appraisal as it has 
been defined by Folkman, Lazarus, Gruen, and DeLongis (1986), and as it will be defined for the purpose of the current study, is an evaluative process in which individuals examine their environment and determine whether it is threatening to their well-being. Lazarus and Folkman (1984) further broke down the appraisal process into primary and secondary appraisals. The primary appraisal involves an individual ascertaining the relevance/irrelevance of a situation, whether it is generally positive (benign-positive) and whether the stressor is harmful, threatening, or challenging. The secondary appraisal process involves how individuals deal with a threatening or challenging situation, essentially an evaluation of the possible coping strategies. Lazarus and Folkman (1984) suggest that this secondary appraisal process is significantly more complex than the primary appraisal because there are a number of coping mechanisms and some may be more effective in a given situation than others. For example, in the case of an abusive supervisor, active coping by scheduling a meeting with the supervisor and a human resource manager might be more effective than seeking emotional support from a family member. Again, as in the primary appraisal, the individual finds himself or herself examining cues from the environment and perhaps weighing the costs and benefits of each coping mechanism. One aim of the proposed stress models, therefore, is to further understand the complexities of this secondary appraisal in the cognitive process.

There are several benefits to studying stress within a cognitive appraisal process framework. For example, examining stress from a cognitive appraisal perspective has the benefit of explaining variations between individuals exposed to comparable situations or stimuli. The cognitive-appraisal model of stress tends to complement earlier theories of behavior and personality. The Big Five personality factors, for example, are thought to 
have a significant influence over cognitive appraisals. Costa and McCrae (1990) recognized the relationship between the individual and his or her environment as determinants of behavior and, in their theoretical work they highlight the particularly important role of trait neuroticism in the appraisal process. Individuals who are predisposed or have the innate tendency to display more neurotic behavior are likely to view a stressful situation in a fundamentally different manner than an emotionally stable individual and, thus, adopt different coping mechanisms. Researchers have found inconsistencies when examining the cognitive appraisal of stress. Perhaps these inconsistencies can be explained by variation in dispositional affect; therefore, personality might be working as a buffer or catalyst in the cognitive appraisal process.

Existing research provides some evidence to suggest individual differences affect the stressor appraisal relationship. For example, Coyne, Aldwin, and Lazarus (1981) found that depressed individuals differ from non-depressed individuals primarily in their emotional regulations: depressed individuals used more maladaptive and emotionfocused coping styles. There was no difference found for problem-focused coping; however, Billings and Moos (1984) found that depressed individuals do not undertake as many difficult problems that require problem-solving coping. Depression is closely related to personality differences in neuroticism, for example, so these findings provide initial support that personality factors influence coping strategies (Costa \& McCrae, 1984). Additionally, Folkman and Lazarus' (1986) cognitive-phenomenological theory suggests stressful events and corresponding emotional outcomes are mediated by cognitive appraisal and coping. Folkman and Lazarus (1986) used a subsample of participants who scored high on a measure of depressive symptoms over the course of a 
6-month period. Their results indicated that participants scoring high on depressive symptoms used more confrontive, self-control, and escape-avoidant coping mechanisms in addition to receiving more social support. Emotional regulation may be one individual difference in the appraisal process, but the literature also suggests that personality traits contribute to this process. Another example of individual differences influencing the adoption of coping styles examined negative trait affect as a predictor (Brown, Westbrook, \& Challagalla, 2005).

There have been two prominent approaches of stress in the literature: traitoriented and process-oriented approaches (Folkman, Lazarus, Dunkel-Schetter, DeLongis, \& Gruen, 1986). The trait-oriented approach, as the name suggests, is a perspective grounded in the idea that the external environment does not significantly influence the coping strategies; rather, an individual's character traits define coping style. The process-oriented approach, on the other hand, is the approach where the environment and psychological demands of a situation influence the adoption of coping styles. These coping approaches and the various behaviors associated with each will be reviewed in greater detail later in the current proposal. The cognitive-appraisal model proposed by Lazarus and colleagues (1984) is primarily concerned with process-oriented coping, selection of coping styles based on environment instead of the individual. In their study, Folkman et al. (1986) found that individuals utilize different coping mechanisms for work-related stressors. Both the trait- and process-oriented theories of stress are valid approaches. One inherent benefit of the process-oriented approach is the implication that individuals are capable of changing their processes and, thus, able to adopt different or more effective coping mechanisms. Moreover, the major benefit of the trait-oriented 
approach is that individuals have some consistency in their use of coping strategies; this approach accommodates for this idea. While they have traditionally been studied independently, the trait and process approaches are not necessarily mutually exclusive (i.e., Cognitive processing does not occur independently of personality and vice versa). One aim of the proposed model of stress, therefore, is to integrate personality, motivational, and cognitive processing components.

\section{Coping Strategies}

Coping, the main component of the secondary appraisal process, is defined as the behavioral or cognitive mechanisms used to alleviate the taxing demands from stressful situation or stimuli; these mechanisms can be problem-focused, emotion-focused, or maladaptive (Folkman et al., 1986). The adoption of a problem-focused coping style occurs when an individual seeks to reduce their experienced stress by doing something to alter the source of stress, and emotion-focused coping style involves an individual seeking emotional support to deal with the distress. Maladaptive coping styles typically involve avoidance behavior or denial (Carver, Scheier, \& Weintraub, 1989). There are several behaviors associated with each overarching coping style according to Carver et al. (1989). The distinctions in behavior that can be made with regard to problem-focused coping strategies include 1) active coping or the attempt to remove the stressor, 2) planning, 3) suppression of competing activities, 4) restraint coping or waiting for an appropriate time to deal with the situation, and 5) seeking social support for instrumental reasons. For emotion-focused coping strategies, there are also several possible coping behaviors including 1) seeking social support for emotional reasons, or 2) focusing on venting of emotions. There has been a considerable amount of research that has examined 
coping styles in clinical populations, but there is a need to assess variation in coping styles at work and how they relate to the way individuals experience strain (KammeyerMueller, Judge, \& Scott, 2009).

The effectiveness of coping strategies in the workplace or an academic setting is fundamentally different than in other external environments such as a clinical setting (Brown, Westbrook, \& Challagalla, 2005). It is necessary for employees to be able to manage negative emotions and resolve problems through the use of adaptive coping means because decreased performance is likely to come with negative repercussions. The adoption of problem-focused coping strategies in the workplace has been found to be effective in alleviating work-related stress, but emotion-focused strategies have not been found to be quite as effective as problem-focused strategies (Parkes, 1990). The few research studies that have investigated the relationship between stress and coping style at work have provided similar results. For example, Boyd, Lewin, and Sager (in press) predicted that role ambiguity (i.e., hindrance stressor) would be negatively related to emotion-focused and problem-focused coping styles and that role conflict (i.e., challenge stressor) would be positively related to both types of coping styles. The results suggest that there is a positive relationship between role conflict, role ambiguity, and emotionfocused coping style and a negative relationship between role ambiguity and problemfocused coping style. In other words, employees rely more heavily on emotional coping instead of dealing with the source of stress for hindrance stressors. Perhaps the venting of emotions is more common for employees experiencing role conflict and ambiguity because they are able to use emotion-focused coping in the family domain rather than in the work domain. In a similar study, Pearsall, Ellis, and Stein (2009) examined how 
individuals in a team situation cope with challenge or hindrance stressors. The essential hypotheses for this study were 1) that when presented there will be a positive influence on team performance and transactive memory and a negative impact on psychological withdrawal and 2) team members will use more problem-focused coping when presented with a challenge stressor and more emotion-focused or maladaptive coping to deal with hindrance stressors. Both of these hypotheses were fully supported, thus, providing further support for the conceptualization that employees should adopt different coping strategies based on the type of stressor. Accordingly, I propose the following hypotheses: $\mathrm{H}_{1 \mathrm{a}}$ : There will be a positive relationship between the level of challenge stressors and problem-solving coping style.

$\mathrm{H}_{1 \mathrm{~b}}$ : There will be a negative relationship between the level of hindrance stressors and problem-solving coping style.

$\mathrm{H}_{2 \mathrm{a}}$ : There will be a negative relationship between the level of challenge stressors and emotion-focused coping style.

$\mathrm{H}_{2 \mathrm{~b}}$ : There will be a positive relationship between the level of hindrance stressors and emotion-focused coping style.

$\mathrm{H}_{3 \mathrm{a}}$ : There will be a negative relationship between the level of challenge stressors and maladaptive coping style.

$\mathrm{H}_{3 \mathrm{~b}}$ : There will be a positive relationship between the level of hindrance stressors and maladaptive coping style.

Core Self-Evaluations and Coping

The secondary appraisal process is complex and research suggests that there may be individual differences that moderate the relationship between stressors and the 
adoption of coping strategies. Specifically, researchers predict that core self-evaluations should have a significant influence in the stressor appraisal process (Kammeyer-Mueller et al., 2009; Folkman et al., 1986; Pearlin, \& Schooler, 1978). The core self-evaluation construct is defined as a broad dispositional trait that includes a collection of subconscious self-appraisals which influence all areas of an individual's external environment (Judge, Locke, \& Durham, 1997). Four personality traits have been categorized under the overarching construct of core self-evaluations according to Judge et al. (1997): self-esteem, generalized self-efficacy, neuroticism, and locus of control. Selfesteem is an individual's thoughts and feelings with reference to the self and emphasis is placed on the appraisal of self-worth (Rosenberg, 1979). An appraisal of the self, generalized self-efficacy is a measure of an individual's overall perceived capability which influences the motivation, cognition, and planning needed for his or her success (Judge et al., 1997). Neuroticism is a broad personality trait which measures various aspects of an individual's emotional stability: anxiety, anger, depression, guilt, and fear (Costa, \& McCrae, 1984). The fourth and final core self-evaluation trait, locus of control, refers to the amount of control individuals perceive they have over their external environment (Rotter, 1966). Individuals who score high on internal locus of control tend to perceive their environment as changeable and they can control the outcomes of situations (Spector, 1982). Individuals with an internal locus of control also value reward systems and contingent rewards for performance because they make an association between a stimulus, response, and outcome in their external environment. There has been some preliminary research which has examined the overarching core self-evaluation trait 
and the appraisal process, but overall these studies have been limited (Kammeyer, et al., 2009; Li \& Yang, 2009).

In one study, Kammeyer et al. (2009) used a meta-analytic procedure, in addition to collecting daily diary data, to determine the influence core self-evaluations have in the appraisal of stress. They predicted that participants scoring high on core self-evaluations would encounter fewer stressful situations because they would not appraise them as such. For example, an individual with high self-esteem and generalized self-efficacy might embrace and thrive on the creative freedom of developing a company newsletter; whereas, someone with low core self-evaluations might feel anxious about not meeting the unclear expectations of the supervisor. Secondly, Kammeyer and colleagues found support for a relationship between stressor and strain would be moderated by core selfevaluations. Furthermore, participants who scored high on core self-evaluations reported more problem-focused, adaptive coping styles instead of maladaptive styles. Results provided support for the importance of core self-evaluations in the cognitive appraisal of stressors. Another recent study used path analysis to determine the relationship specifically between self-efficacy and coping style (Li \& Yang, 2009). Their analysis suggested that relationship between self-efficacy and problem-focused coping style was more effective than between attachment type and coping style. Similarly, Boyd, et al. (in press) found that self-efficacy was negatively associated with emotion-focused coping style, but their hypothesis that self-efficacy would be positively associated with problemfocused coping style was not supported. In summary, believing or having confidence in one's capabilities on the whole was related to addressing the stressor constructively in one study, but these results may not be universal. 
Core self-evaluations have been predicted to buffer the negative effects of social stressors on turnover, job satisfaction, and many other organizational outcome variables. Interestingly, Lazarus and Folkman (1984) suggest that one important component of the primary appraisal process involves individuals determining whether a stimulus will deplete their resources. In their study of social stressors, Harris, Harvey, and Kacmar (2009) utilized the Conservation of Resources theory (Hobfoll, 1989) to suggest core self-evaluations would act as a moderator between stressors and coping style. It was found that participants scoring higher on core self-evaluations were more equipped to deal with social stressors than participants scoring low on the same traits, perhaps because they appraised themselves as having the resources necessary to cope. Jex, Bliese, Bruzzell, and Primeau (2001) also found moderating effects for self-efficacy and they were strongest when participants scored high on problem-focused and low on avoidance coping. Although there have been some inconsistencies in results from these studies, it is predicted that core self-evaluations will moderate the relationship between stressor and coping style. In accordance with the aforementioned theoretical findings, the following hypotheses have been proposed:

$\mathrm{H}_{4 a}$ : Core self-evaluations will moderate the relationship between challenge stressors and coping style, such that higher levels of core self-evaluations will result in greater problem-focused coping. $\mathrm{H}_{4 \mathrm{~b}}$ : Core self-evaluations will moderate the relationship between hindrance stressors and coping style, such that lower levels of core self-evaluation will result in greater emotion-focused coping. 
$\mathrm{H}_{4 \mathrm{c}}$ : Core self-evaluations will moderate the relationship between hindrance stressors and coping style, such that lower levels of core self-evaluation will result in greater maladaptive coping. Motivation and Coping

As previously mentioned, motivation has been considered an important individual difference with regard to the challenge-hindrance stressor models (LePine et al., 2004). Previous research has viewed motivation as an outcome of the coping process; however, conceptualizing motivation in terms of self-determined work behavior might act as a moderator of the appraisal process (Lam \& Gurland, 2008). Self-determination as defined by Deci and Ryan (1985) is an individual's choice to engage in behavior for autonomous reasons rather than for rewards or because of coercion. Their concept of selfdetermination has also been commonly referred to as intrinsic motivation, the motivation to engage in a task simply because of the nature of that particular task is interesting, engaging, or satisfying (Amabile, Hill, Hennessey, \& Tighe, 1994). Another type of motivation outlined by Deci and Ryan (1985) has been referred to as extrinsic motivation, the motivation to engage in a task as the result of an anticipated reward or recognition. The primary appraisal in the transactional model of stress is based on the appraisal of resources; it is expected that this particular theory of motivation will complement the proposed model. The saliency of the desire for reward experienced by extrinsically motivated individuals is likely to significantly influence the appraisal process because challenge stressors are characterized by perceived rewards or benefits.

Research findings in this area of study have provided initial evidence to suggest motivation (i.e., intrinsic and extrinsic) might act as a moderator of the relationship 
between appraised stressors and coping style. In one study of self-determined work motivation, higher levels were associated with greater work satisfaction and less emotional exhaustion (Richer, Blanchard, \& Vallerand, 2002). Perhaps, more intrinsically motivated individuals cognitively appraise a stressor as more manageable than those who are less intrinsically motivated; as a result, these individuals may more frequently adopt a problem-focused coping style. It is important to note that in an academic setting intrinsic motivation has been associated with a deeper level of processing with regard to studying exam materials (Moneta \& Spada, 2009). These findings suggested that motivation influence the problem-focused and maladaptive types of coping. Moneta and Spada (2009) made an important distinction when they suggested that students who were intrinsically motivated used grades as an indicator of performance; whereas, students who were more extrinsically motivated perceived grades as an ego-based reward. In a work environment, extrinsically motivated employees seek various types of rewards such as salary, promotions, bonuses, praise, or recognition (Deci \& Ryan, 1985). Additionally, in their model of stress and coping style, Li and Yang (2009) posited that motivation would act as a mediator between stressors and coping style. What this suggests is that motivation is what actually results in the adoption of either adaptive or maladaptive coping mechanisms. The problem with this conceptualization of the relationship is that it cannot account for the possibility motivation affects the magnitude of the predictorcriterion relationship (i.e., acts as a moderator between stressor type and coping mechanism).

The current state of motivation theory is conceptually disjointed, but the categorization of motivation as intrinsic and extrinsic is one of the most influential 
frameworks (Leonard, Beuvais, \& Scholl, 1999). In their theoretical piece, Leonard et al. (1999) attempted to integrate several motivational theories and, in doing so, they suggested that there is an appraisal of actual traits, competencies, and values that dictate level of motivation. In fact, Leonard et al. (1999) proposed a meta-theory that suggested every individual has a dominating motivational factor: intrinsic, extrinsic/reward, selfconcept (social drive), internal self-concept (affirmation drive), or goal internalization (task drive). Paralleling these findings, Amabile et al. (1994) found evidence to suggest intrinsic and extrinsic motivations are not opposite ends of the same continuum. Results from their study indicated that individuals can simultaneously score high on both intrinsic and extrinsic motivation subscales. It is possible, for example, for an employee to be motivated by the type of work he or she does and by the monetary incentives they receive because of their work. For the purposes of the proposed transactional cognitive-appraisal model of stress, it is predicted that individuals with either intrinsic, extrinsic, or both intrinsic and extrinsic motivation orientations will be more inclined to use more adaptive coping styles instead of maladaptive styles.

$\mathrm{H}_{5 \mathrm{a}}$ : Extrinsic motivation will moderate the relationship between challenge stressors and coping style, such that higher levels of extrinsic motivation will result in greater problemfocused coping. $\mathrm{H}_{5 b}$ : Extrinsic motivation will moderate the relationship between hindrance stressors and coping style, such that lower levels of extrinsic motivation will result in greater emotionfocused coping. 
$\mathrm{H}_{5 \mathrm{c}}$ : Extrinsic motivation will moderate the relationship between hindrance stressors and coping style, such that lower levels of extrinsic motivation will result in greater maladaptive coping. $\mathrm{H}_{6 \mathrm{a}}$ : Intrinsic motivation will moderate the relationship between challenge stressors and coping style, such that higher levels of intrinsic motivation will result in greater problemfocused coping.

$\mathrm{H}_{6 \mathrm{~b}}$ : Intrinsic motivation will moderate the relationship between hindrance stressors and coping style, such that lower levels of intrinsic motivation will result in greater emotionfocused coping.

$\mathrm{H}_{6 c}$ : Intrinsic motivation will moderate the relationship between hindrance stressors and coping style, such that lower levels of intrinsic motivation will result in greater maladaptive coping.

Coping and Performance

The primary objective for researchers interested in coping and performance has been to determine consistent relationships between stressors and performance. Adopting the challenge and hindrance model of stress, Gilboa, Shirom, Fried, and Cooper (2008) conducted a meta-analysis to aggregate the correlations from existing literature. Their hypotheses, in accordance with Lazarus and Folkman's theory (1984), were that hindrance stressors would be negatively related to job performance and that challenge stressors would be positively related to performance. Within the challenge-hindrance framework of stressors, Gilboa et al. (2008) predicted that there would be differences in the deleterious effects of hindrances. Their results provided evidence to suggest role ambiguity had a greater negative influence over job performance, perhaps because fewer 
coping mechanisms could be adopted to ameliorate this particular stressor. These findings suggest that the type of stressor should be examined to effectively understand the impact of stress on employee overall job performance.

With regard to the relationship between stressor and performance, it is essential to investigate the role of coping style. The current literature suggests that some coping mechanisms or strategies are more adaptive than others; specifically, problem-focused has been associated with the adaptive form of coping, followed by emotion-focused and maladaptive styles (Mantler, Matejicek, Matheson, \& Ainsman, 2005; Carlson \& Perrewe, 1999; Stetz, Stetz, \& Bliese, 2006; Bhagat, Allie, \& Ford, 1991). In fact, Bhagat et al. (1991) found that problem-focused coping style mediated the relationship between stressors and strain, whereas emotion-focused coping styles did not mediate the stressorstrain relationship. Specifically, Bhagat and colleagues (1991) provide evidence to suggest problem-focused coping style is less likely to lead to the adverse physical and psychological effects of stress. One explanation for this reduction of physical and psychological effects is that problem-focused coping eliminates the stressor, thus, providing more lasting relief. While there have been numerous hypotheses to suggest how the strain in the workplace is experienced, the relationship with performance outcomes has not been studied extensively (Stetz, et al., 2006; Weiss \& Cropanzano, 1996; Brown et al., 2005). Intuitively, experiencing more negative physical and psychological symptoms should be significantly predictive of decreased performance regardless of the domain (i.e., work, school, or home). Paralleling the stress-performance relationship, in their study of the emotion-performance relationship, Brown et al. (2005) tested three hypotheses regarding the moderation effects of task focus (i.e., problem- 
focused coping), self-control (i.e., a combination of problem-focused and emotionfocused coping), and venting (i.e., emotion-focused coping). Their results suggested that problem-focused coping strategies moderated the relationship between negative emotions and employee performance, while emotion-focused coping exacerbated the effects of negative emotion on performance. Additionally, Stetz and colleagues (2006) posit that emotional support and self-efficacy moderate the relationship between stressor and strain. Taking into account the literature that suggests strains are directly related to performance outcomes, the following hypotheses have been developed.

$\mathrm{H}_{7 \mathrm{a}}$ : There will be a positive relationship between challenge stressors and performance. $\mathrm{H}_{7 \mathrm{~b}}$ : There will be a negative relationship between hindrance stressors and performance. $\mathrm{H}_{8}$ : Coping style will moderate the relationship between stressors and performance, such that problem-focused coping will reduce the deleterious effects of stress.

$\mathrm{H}_{9}$ : Coping style will moderate the relationship between stressors and performance, such that emotion-focused and maladaptive coping will increase the deleterious effects of stress.

Coping and Satisfaction

There has been recent attention given to the relationship between coping strategy and well-being in the form of job satisfaction (Welbourne et al., 2007). Studies that have empirically linked stressors, coping strategy, and job satisfaction have predicted a direct relationship between stressor, strain, and job satisfaction (Fogarty, Machin, Albion, Sutherland, Lalor, \& Revitt, 1999). Fogarty et al. (1999) developed a model of the stressor-strain relationship which included job satisfaction. In this model, they found support to suggest individuals' experience of strain is negatively related to job 
satisfaction. The path analysis provided evidence to suggest strain incrementally predicted job satisfaction above and beyond coping strategy. These findings basically suggest that regardless of the type of stressor more perceived stress will lead to dissatisfaction. What this study does not suggest is that coping style might actually moderate the adverse effects of stress on satisfaction. Expanding upon existing literature, Welbourne et al. (2007) predicted that individuals who employ a more problem-focused coping strategy would also be more likely to perceive a stressful work situation as positive and, thus, report more job satisfaction than those individuals who employ a more maladaptive coping approach. The results from this particular study supported their suppositions, in that participants reporting more problem-focused and emotion-focused coping styles had significantly higher job satisfaction as compared to those who reported maladaptive coping behaviors. One particularly interesting finding from this study was that emotion-focused coping was positively related to satisfaction perhaps because catharsis (i.e., the outward expression of emotions) helped to regulate dispositional affect (Bloom-Feshbach \& Bloom-Feshback, 2001). On the basis of these findings, the following hypotheses will be tested:

$\mathrm{H}_{10 \mathrm{a}}$ : There will be a positive relationship between challenge stressors and domain satisfaction.

$\mathrm{H}_{10 \mathrm{~b}}$ : There will be a negative relationship between hindrance stressors and domain satisfaction.

$\mathrm{H}_{11}$ : Coping style will moderate the relationship between stressors and domain satisfaction, such that problem-focused and emotion-focused coping will reduce the deleterious effects of stress. 
$\mathrm{H}_{12}$ : Coping style will moderate the relationship between stressors and domain satisfaction, such that maladaptive coping will increase the deleterious effects of stress. The Proposed Model

The purpose of the current study is to integrate the existing literature into a testable, comprehensive model to provide a greater understanding of the cognitive appraisal process of stressors. Using the challenge-hindrance framework, the current study examines individual differences in motivation and core self-evaluations as potential moderators of the relationship between stressors and coping style. Another aim of the model is to more thoroughly explain the individual differences that contribute to the stressor-performance and stressor-satisfaction relationship and how coping strategy acts as a moderator of the stressor-performance relationship. The cognitive-appraisal approach to stress as initially conceptualized by Lazarus and Folkman (1984) lends itself to individual differences in the perception of stressors. Therefore, a secondary aim of the proposed model is to provide a framework that allows for both trait- and process-oriented approaches to stress. Two separate models of stress and coping style will be proposed: one will indicate the predicted relationships for challenge stressors and the directionality of those relationships (see figure 1) and the second will indicate the predicted relationships for hindrance stressors and the directionality of those relationships (see figure 2).

\section{CHAPTER III - METHODOLOGY}

Participants

The first sample of participants were undergraduate students currently enrolled at Florida International University who were at least 18 years of age (to provide informed 
consent). Recruitment of participants was done through the campus-wide SONA systems online data collection website. Data were collected from 538 men and women to ensure sufficient power to detect interaction effects. Students were asked whether they were currently employed, but employment was not a prerequisite for participation in the current study. There has been some debate surrounding the use of college student samples for the purposes of social science and organizational behavior research (Gordon, Slade, \& Schmitt, 1986; Greenberg, 1987; Peterson, 2001). The general finding was that student sample scores may be slightly more homogeneous than non-student samples (Peterson, 2001); however, analyzing the scores of a work sample from a single organization lends itself to similar methodological issues because of the possible homogeneity of an organization's climate or culture (Greenberg, 1987). A student sample was utilized for the purposes of the proposed model to provide an initial test of the hypothesized linkages, in part, because of the accessibility of student participants.

The second sample of participants were men and women currently holding parttime or full-time employment for at least 20 hours per week. A snowball sampling technique was used to collect online data from working participants. The SONA online research webpage was used to notify Florida International University students of the study, and students received extra credit toward an Introductory Psychology course for referring individuals who met the study qualifications. Participants from the working sample had to be 18 years of age to provide informed consent. The snowball sampling design did not yield the anticipated number of participants, and as a result there was not enough power to conduct interaction analyses. A total of 108 employees completed the time one survey, but only 44 completed the time two survey. Out of the participants who 
completed both portions of the study, fifteen responses were omitted either because employees did not provide the email address to link data or because they did not fully complete the scale items. A total of 29 responses were used for the correlation analysis (see appendix). The aim of having two samples was that it would increase the generalizability and confidence of the study results.

Procedure

Participants signed-in to access their SONA systems account at which time they were redirected to the online survey materials hosted by Survey Monkey. A brief description with enough information for students to make an informed decision whether or not they would like to participate was provided prior to the online consent form. Participants completed survey items in two separate sessions: during the first session participants completed the challenge-hindrance stress scale and core self-evaluation assessments; during the second session, participants completed the motivation, coping, satisfaction, and performance measures. Before both sessions, participants read about what that portion of the project would entail and electronically provide consent. Following the consent, participants indicated the degree to which each statement is true for them. Once participants completed the scale portion of the survey on the first session, they were asked a series of demographic questions that included age, gender, and ethnicity. Participants were asked to provide their Panther ID for the purposes of linking time one and time two data. Students had the option to allow me to use their ID number for the purposes of GPA verification. To ensure confidentiality, at no point during the study were Panther ID numbers linked to any of the scales for individual analysis; rather, once the time one and time two links had been verified, and applicable GPA data had 
been collected, Panther ID's were no longer used. Only aggregated, group-level data were analyzed. Upon completion of the study, participants received research credit toward a psychology course.

Study One - Measures

School challenge-hindrance stressors. The 10-item Stressor Scale, developed to assess challenge and hindrance stressors of students, was used in study one of the current study (LePine, et al., 2004). These scale items were developed from a collection of critical incidents and were then categorized into challenge or hindrance stressors using the Q-sort procedure. The internal consistency reliabilities for the challenge and hindrance subscales were .85 and .70 , respectively. To assess the discriminant and convergent validity of the subscales, both challenge and hindrance factors were loaded onto a single latent variable and fit indices were examined to determine whether these subscales were indeed measuring unique types of stressors. On the basis of these analyses, this scale demonstrated adequate convergent and discriminant validity. Participants responded on a Likert scale $(1=$ No stress to $5=A$ great deal of stress $)$ to each statement and indicated the level of stress each circumstance produced.

Coping style. The complete COPE scales measure consists of 53 items; however, for the purpose of the current study (i.e., both student and working samples), only 36 items were used (Carver et al., 1989). The subscales that do not directly pertain to problem-focused, emotion-focused, or maladaptive coping strategies were omitted: the positive reinforcement and growth, acceptance, turning to religion, denial, and alcohol-drug disengagement subscales. The internal consistency reliability estimates for the subscales were as follows: active coping (.62), planning (.80), suppression of competing activities 
(.68), restraint coping (.72), seeking social support instrumental (.75), seeking social support emotional (.85), venting emotions (.77), behavior disengagement (.63), and mental disengagement (.45). The reliability estimates for the subscales were acceptably high with the exception of mental disengagement; however, developers attribute this to the breadth of the criteria being measured. The test-retest reliability for the subscales after an 8 -week period was somewhat low ranging from .46 to .86 . The content of items on various subscales are rather unique, so discriminant and convergent validity estimates were estimated based on subscale rather than the overall coping strategies. Carver et al. (1989) found that problem-focused coping strategies were moderately high correlated with personality traits that correspond with performance; however, authors suggest that the correlations with personality traits also provide discriminant validity because coping strategies did not appear to be identical. Furthermore, the COPE scales demonstrated adequate discriminant validity because they were not highly correlated with social desirability. The COPE scales were used in the current study primarily because, unlike other scales (i.e., Ways of Coping scale, w.c.,Folkman \& Lazarus, 1980), this scale includes subscales to distinguish behaviors within the overarching coping style. For example, within problem-focused coping, the COPE scale allows for the assessment of planning or active coping as individual behaviors. Although the COPE scale was originally developed for use in a clinical setting, it has become a common measure in academic and organizational research studies. Participants responded to statements on a 4-point Likert scale ( 1 = I usually don't do this at all, $2=$ I usually do this a little bit, $3=$ I usually do this a medium amount, $4=$ I usually do this a lot). 
Core self-evaluations. Core self-evaluations were measured for both the student and working samples using the 12-item Core Self-Evaluation Scale [CSES] (Judge, Erez, Bono, \& Thoresen, 2003). In an initial validation study, Judge et al. (2003) found that the internal consistency reliability estimates for subscale scores were all above .80 and an average coefficient alpha of .84. The CSES scale has demonstrated adequate convergent and discriminant validity: there was only a moderate correlation with the Big-Five personality characteristics as anticipated and strong correlations with self-esteem, generalized self-efficacy, and locus of control measures (Judge et al., 2003). Participants responded to the statements on a Likert scale $(1=$ Strongly Disagree, $2=$ Disagree, $3=$ Neutral, 4= Agree, 5= Strongly Agree).

Motivation. The 30-item Work Preference Inventory (Amabile, Hill, Hennessey, \& Tighe, 1994) was used to assess both intrinsic and extrinsic motivation preference. In a validation study, Amabile et al. (1994) found that the internal consistency reliability estimates for the intrinsic and extrinsic motivation scales were .79 and .78 , respectively. The test-retest reliability after a 6-month period was high for both the intrinsic and extrinsic scales at .84 and .94 , respectively. This scale has demonstrated adequate convergent and discriminant validity: there was not a strong relationship between the motivation scales, social desirability, and sheer intelligence, but there were strong relationships between the Work Preference Inventory and other motivation scales (Amabile et al., 1994). The Work Preference Inventory was originally validated on both a work and student sample and test developers made the necessary changes to accommodate for the student sample. For example, the statement "I am strongly motivated by the money I can earn" was replaced with "I am strongly motivated by the 
grades I can earn." Both versions of the Work Preference Inventory were used for the current study: the student version for sample one and the work version for sample two. Participants responded to the statements on a Likert scale $(1=$ Never or Almost Never True of Me to 5= Always or Almost Always True of Me).

School performance. Four items taken from the School Readiness Scale (Markel \& Frone, 1998) were used to measure self-report school performance for the student sample in study one of the current proposal. These items are representative of the students' attendance, effort in class and on assignments, and preparedness of assignments and class materials. The internal consistencies for the various subscales were all relatively high: attendance (.81), effort (.73), and preparedness (.72). Participants rated the frequency of these statements on a 5 -point, Likert-type scale $(1=$ never to $5=$ very often $)$.

School satisfaction. The 6-item school satisfaction scale developed by Butler (2007) was used only for the student sample. The internal consistency reliability for this scale in the original study was .95. In the current study, participants responded to statements on a 5point Likert scale $(1=$ Strongly Disagree to $5=$ Strongly Agree $)$.

Study Two - Measures

Work challenge-hindrance stressors. The 11-item Challenge-Hindrance Stress Measure, developed to assess stressors in the workplace, was be used for the working sample, study two of the current thesis (Cavanaugh et al., 2000). Challenge items were developed to measure work domain-related stressors that have potential positive outcomes: job overload, time pressure, and level of responsibility. Hindrance items included stressors such as organizational politics, red tape, and job insecurity. The factor structure of the Challenge-Hindrance Stress Measure was tested using a confirmatory factor analysis and 
results indicated that the two-factor model fit better than a one-factor model (Cavanaugh et al., 2000). The challenge and hindrance subscales showed high internal consistency estimates, .87 and .75 , respectively. The challenge-hindrance scale also demonstrated adequate convergent and discriminant validity because both stressor subscales were positively related to neuroticism and negatively related to extroversion. In addition to the confirmatory factor analysis results, the validation study found a low (.28) correlation between the challenge and hindrance subscale which provides additional discriminant validity. Coping Style, Core Self-Evaluations, and Motivation. The same scales as described for study one were also used for the employee sample. The only modifications made for the employee sample were done with regard to the motivation scale. Rather than using the adapted version for academic motivation, the original items that tapped into work motivation preference were used (e.g., I am strongly motivated by the money I can earn). Job Performance. Job performance was measured using the four-item in-role performance subscale from Van Dyne and LePine (1998). Sample items include "I meet performance expectations at work" and "I perform the tasks that are expected as part of my job." The validation study consisted of two separate samples; the internal consistency reliabilities for this original study were .85 and .86 . Researchers tested the construct validity of the three subscales using factor analysis; the in-role subscale items loaded on the same latent factor. In Van Dyne and LePine's validation study (1998), hierarchical regression was used to provide an estimate of predictive validity. Specifically, when controlling for age, tenure, education, firm type, and job level, the in-role subscale items explained more 
variance in performance (adjusted $\mathrm{R}^{2}=.04$ ). In the current study, participants responded to statements on a 5-point Likert scale $(1=$ Strongly Disagree to $5=$ Strongly Agree $)$. Job satisfaction. The Hackman and Oldham (1975) 3-item general scale was used to assess work domain satisfaction for the snowball sample in study two of the current study. The internal consistency reliability for the validation study was adequate at .76. Participants will respond to statements on a 5-point Likert scale (1 = Strongly Disagree, 2 = Disagree, 3 = Neutral, 4 = Agree, $5=$ Strongly Agree .

Analysis

To test the predicted linkages in the proposed models, a series of multiple regression analyses were conducted (Aiken \& West, 1991; Cohen \& Cohen, 1983). Moderated regression was used to determine the effect of moderating variables (i.e., intrinsic motivation, extrinsic motivation, and core self-evaluations) on the predictorcriterion relationships (Saunders, 1956; Zedeck, 1971). The partial regression coefficient was examined to estimate the moderating effects (McClelland \& Judd, 1993).

Furthermore, it has been suggested that hierarchical regression be used to test whether the interaction is reliably different from zero when controlling for the individual terms (Aiken \& West, 1991; Cohen \& Cohen, 1983). One criticism of moderated regression analysis, however, has been that it only differentiates between subgroups because of measurement error (Zedeck, 1971). To minimize the negative effects of measurement error, corrections were made to the scale scores for the predictor variables.

For hypotheses $\mathrm{H}_{1 \mathrm{a}}$ through $\mathrm{H}_{3 \mathrm{~b}}$, responses on each individual subscale were aggregated: problem-focused items were aggregated, emotion-focused items were aggregated separately, and maladaptive items were aggregated separately. The challenge- 
hindrance stress scores were entered at step 1 and aggregated coping subscales were entered at step 2. Once these individual terms have been entered, they were centered and the interaction term was entered. The beta weights were used to determine the directionality and strength of the relationship between stressor type (i.e., challenge or hindrance) and coping style. A moderated regression was conducted to test whether the relationship between stressor type and coping style varies as a function of the aggregate of the core self-evaluations subscales (hypotheses $\mathrm{H}_{4 \mathrm{a}}$ and $\mathrm{H}_{4 \mathrm{c}}$ ). Consistent with the suggestions of Cohen and Cohen (1983), challenge-hindrance stress was entered at step 1 and the aggregate of each individual core self-evaluation (i.e., self-esteem, self-efficacy, neuroticism, and locus of control) and the interaction term was entered at step 2. Similarly, a moderated regression was conducted to test whether the relationship between stressor type and coping style varies as a function of both extrinsic and intrinsic motivations (hypotheses $\mathrm{H}_{5 \mathrm{a}}$ through $\mathrm{H}_{5 \mathrm{c}}$ and $\mathrm{H}_{6 \mathrm{a}}$ through $\mathrm{H}_{6 \mathrm{c}}$ ). To test the relationship between stressor type and performance (hypotheses $\mathrm{H}_{7 \mathrm{a}}$ and $\mathrm{H}_{7 \mathrm{~b}}$ ), the aggregate of responses on the School Readiness items was entered into the regression equation and beta weights were examined to determine the strength and direction of the relationships (hypotheses $\mathrm{H}_{8}$ and $\mathrm{H}_{9}$ ). A moderated regression analysis was conducted to test whether coping style would moderate the relationship between stressor type and school performance; the individual beta weights as well as the interaction beta weight were used to test hypotheses $\mathrm{H}_{7 \mathrm{a}}$ and $\mathrm{H}_{7 \mathrm{~b}}$. For the hypotheses $\mathrm{H}_{10 \mathrm{a}}$ through $\mathrm{H}_{10 \mathrm{~b}}$, a multiple regression was conducted with the aggregate of each domain-specific satisfaction scale score and stressor type; beta weights were used to indicate the magnitude of these predictors and the directionality of these relationships (hypotheses $\mathrm{H}_{11}$ and $\mathrm{H}_{12}$ ). 
Because the Core Self-Evaluation Scale (CSES) was developed as an overarching factor that is composed of four subscales but items do not exclusively measure one subscale trait, a post-hoc exploratory factor analysis was conducted on the Core SelfEvaluation Scale to determine which items loaded onto each of four factors. Following the factor analysis, items that loaded best on each of the four factors were aggregated to form self-esteem, neuroticism, self-efficacy, and locus of control subscales. Using a similar method as described above, a series of regression analyses were conducted to determine whether each individual facet also moderated the relationship between student stress and problem-focused coping (refer to figures 5 through 7 for significant interaction graphs and table 7 for beta weights).

\section{CHAPTER IV - RESULTS}

Hypotheses $1 \mathrm{a}$ and $1 \mathrm{~b}$ were developed to examine stressor types (i.e., challenge/hindrance) as they relate to problem-focused coping. Previous studies and theory suggest that challenge stressors involve an anticipated reward, so it is more likely that people deal with these stressors directly through problem-focused strategies and planning. Hypothesis 1a was not supported; results suggest that there is no significant relationship between challenge stress and problem-focused coping. Conversely, extant literature supports the notion that hindrance stressors have no potential reward, so there should be a negative relationship between hindrance stressors and problem-focus coping. Hypothesis $1 \mathrm{~b}$ was not supported; results suggest there is no significant relationship between hindrance stress and problem-focused coping (see Table 1 for correlation coefficients). Hypotheses $2 \mathrm{a}$ and $2 \mathrm{~b}$ were developed to examine the stressor types as they relate to emotion-focused coping. As previously mentioned, it has been hypothesized that 
challenge stressors are related to problem-solving and, thus, the alleviation of the stressor. Hypothesis 2a examined the relationship between challenge stress and the use of emotion-focused coping. Results suggest a significant and positive relationship between challenge stress and emotion-focused coping through venting, and/or seeking social support (see Table 1 for correlation coefficients). Because hindrance stressors are inherently more difficult to alleviate, it was predicted that hindrance stress would be positively related to emotion-focused coping. Correlational data provide evidence in support for Hypothesis $2 b$, such that, students reporting more hindrance stressors also reported more emotion-focused coping. Hypotheses $3 \mathrm{a}$ and $3 \mathrm{~b}$ were developed to determine whether the type of stressor was related to the prevalence of maladaptive coping. Similar to predictions regarding emotion-focused coping, it was predicted that challenge stressors would be negatively related to avoidance (H3a) and hindrance stressors positively related to avoidance (H3b). Results did not support Hypothesis 3a because there was a significant positive relationship between hindrance stress and maladaptive coping; however, result provide evidence to support Hypothesis $3 \mathrm{~b}$ (see Table 1 for correlation coefficients).

Considering the function of core self-evaluations (CSE) as the way individuals view themselves and their capabilities in all situations, hypotheses $4 a, 4 b$, and $4 c$ examine the influence of core self-evaluations on the adoption of coping styles. Moderated regression results support Hypothesis 4a; there were significant main effects (i.e., challenge stress and CSES) and interaction effects (i.e., challenge stress X CSES). The main effect for challenge, however, was only significant when core self-evaluations were added into the regression because the correlation between challenge stress and problem- 
focused coping was non-significant (see Table 1). Evidence suggests that individuals reporting higher CSE also used more problem-focused coping, in both the challenge and hindrance stress models (see Table 2 and 3 for beta weights and r-squared values). Hypotheses $4 \mathrm{~b}$ and $4 \mathrm{c}$ predicted that CSE would moderate the relationship between stressor type, emotion-focused coping, and maladaptive coping. A series of moderated regressions revealed that there were no significant interactions between stressor and CSE when predicting emotion-focused or maladaptive coping (see Table 2 and 3 for beta weights and r-squared values). There was, however, a significant main effect for stressor type (i.e., challenge and hindrance) in predicting emotion-focused coping. Furthermore, there was a significant main effect for CSES in predicting maladaptive coping strategies (see Figures 3-4 for graphs of significant interaction effects).

Although core self-evaluations have been theoretically described as a single overarching personality construct, it is comprised of four somewhat distinct facets of personality. Given that there was a significant moderation for core self-evaluations on the relationship between challenge stress and problem-focused coping and there are distinct facets, a post-hoc analysis was conducted to determine whether one particular trait influenced coping behavior. An exploratory factor analysis was conducted and the four facets of core self-evaluations were identified; subscales were determined based on items that loaded strongest onto each factor. Results from the post-hoc exploratory factor analysis did not indicate any single core self-evaluation trait that moderated the stressorcoping relationship more than the others (see Table 17-20 and Figures 5-12).

On the basis of the cognitive appraisals of stressors and the influence of motivation in that process, hypotheses 5 a through $5 \mathrm{c}$ examined extrinsic motivation as a 
moderator of the relationship between stressor type and coping style. For Hypothesis 5a, it was predicted that extrinsic motivation would moderate the relationship between challenge stressor and problem-focused coping. There was a main effect for extrinsic motivation as a predictor, but no main effect for challenge stressor and no significant interaction effect (see Table 4 for beta weights and r-squared values). Therefore, data do not provide sufficient evidence to support Hypothesis 5a. Extrinsic motivation was predicted to moderate the relationship between hindrance stress and emotion-focused coping style (H5b). When testing the moderation in the hindrance model, there was a main effect for extrinsic motivation, but no main effect for hindrance stressors and no interaction effects (see Table 5 for beta weights and r-squared values). Data do not provide sufficient evidence to suggest extrinsic motivation moderates the relationship between stressor and emotion-focused coping style; therefore, there is not enough support for Hypothesis 5b. For Hypothesis 5c, it was predicted that extrinsic motivation would moderate the relationship between hindrance stress and maladaptive coping. There was a significant main effect for hindrance stress, but no significant main effects were found for extrinsic motivation and no interaction effects. Results, therefore, do not provide evidence to support the moderation proposed in Hypothesis 5c.

Similar to the predictions made for extrinsic motivation, hypotheses 6a through 6c propose that intrinsic motivation will act as a moderator in the relationships between challenge stress and problem-focused coping; hindrance stress and emotion-focused coping; and hindrance stress and maladaptive coping. While extrinsic motivation is involved in the cognitive appraisal process because it is related to monetary rewards or recognition, intrinsic motivation is also related to this process because the individual 
inherently derives pleasure from a given task (i.e., school or work). In Hypothesis 6a, it was proposed that intrinsic motivation would moderate the relationship between challenge stress and problem-focused coping style. Results suggest that there is a significant main effect for intrinsic motivation and challenge stressors, but no significant interaction effects were found (see Table 6 for beta weights and r-squared values). Moderated regression data do not provide sufficient evidence to support Hypothesis 6a. It was predicted that lower levels of intrinsic motivation would be related to greater emotion-focused coping; thus, intrinsic motivation would be acting as a moderator between hindrance stress and emotion-focused coping. For the hindrance stressor moderated regression, there were significant main effects for hindrance stressors and intrinsic motivation, but interaction effect was not significant (see Table 7). Therefore, there results do not support Hypothesis $6 \mathrm{~b}$. Intrinsic motivation was also predicted to moderate the relationship between challenge stress and maladaptive coping style in Hypothesis $6 \mathrm{c}$. The results suggest significant main effects for hindrance stress and intrinsic motivation, but no significant interactions were found (see Table 7). Therefore, the moderated regression data for the student sample do not support Hypothesis $6 \mathrm{c}$.

To test the predicted relationships between self-reported school performance and stressors (Hypotheses 7a and 7b), a bivariate correlation was conducted. There was a significant and positive correlation between challenge stressors and self-reported school performance $(r=.09, p<.05)$ which provides initial support for Hypothesis $7 \mathrm{a}$. The relationship between hindrance stressors and self-reported school performance was nonsignificant, thus, not supporting Hypothesis $7 \mathrm{~b}$. When the same relationships between challenge and hindrance stressors and performance were conducted, but using GPA 
instead of self-reported performance, both correlations were non-significant. With regard to performance, it was predicted that coping style would moderate the relationship between challenge stressors and student academic performance (Hypotheses 8). For the relationship between challenge stressors and self-reported performance, there was a main effect for problem-focused coping, but no significant main effect for performance and no interaction effects (see Table 8 for beta weights and r-squared values). For hindrance stressors, there was a main effect for problem-focused coping but no main effect for hindrance stress (see Table 9 for beta weights and r-squared values). The lack of interaction effects for both challenge and hindrance stressors in these moderated regressions do not provide support for Hypothesis 8 .

To test Hypothesis 9, several moderated regressions were conducted. There were no significant main effects or interaction effect for emotion-focused coping and challenge stress, so evidence suggests the relationship between challenge stressors and self-report academic performance is not moderated by emotion-focused coping. For the moderated regression testing whether emotion-focused coping moderated the relationship between hindrance stressor and academic performance, there was only a main effect for emotionfocused coping and no interaction effect (see Tables 10 and 11 for beta weights and rsquared values). The moderated regression for maladaptive coping yielded significant main effects for maladaptive coping and self-reported academic performance, but no significant interaction was found. When testing maladaptive coping as a moderator of the relationship between hindrance stressors and academic performance, results suggested significant main effects for maladaptive coping and academic performance, but no significant interaction was found (see Table 12 and 13 for beta weights and r-squared 
values). Again, the same moderated regression analyses were conducted using GPA as a measure of student academic performance and there were no significant main effects or interaction effects. The number of students who consented to the retrieval of their GPA $(\mathrm{N}=184)$ was much smaller than the total number of respondents $(\mathrm{N}=538)$; it is likely that these result reflect a lack of power for the interaction analyses.

To test the predicted relationships between self-reported school satisfaction and stressors (hypotheses 10a and 10b), a bivariate correlation was conducted. The relationship between school satisfaction and challenge stressors was not significant which does not support Hypothesis 10a. There was, however, a significant and negative relationship between hindrance stressors and school satisfaction $(r=-.13 p<.01)$, thus, supporting Hypothesis $10 \mathrm{~b}$.

It was predicted that problem-focused and emotion-focused coping would reduce the deleterious effects of stress on self-reported satisfaction (Hypothesis 11) and that maladaptive coping would increase the deleterious effects of stress on self-reported satisfaction (Hypothesis 12). The regression analysis for problem-focused coping as a moderator of challenge stress and satisfaction yielded a significant main effect for coping but not for challenge stress and no interaction effects. For hindrance stress, there were significant main effects for problem-focused coping and stress but no interaction effects (see Table 14 for beta weights and r-squared values). When emotion-focused coping was tested as a potential moderator of the relationship between challenge stress and satisfaction, there were no main effects or interaction effects (see Table 15 for beta weights and r-squared values). Looking at the predicted moderation for emotion-focused coping on hindrance stress and satisfaction, the results suggest that there is a main effect 
only for hindrance stress and no interaction effects. Taken together, these results do not provide support for Hypothesis 11. A similar moderated regression analysis was used to investigate whether maladaptive coping influenced the relationship between stress and satisfaction (see Table 16 for beta weights and r-squared values). In the relationship between challenge stress and satisfaction, there was only a significant main effect for maladaptive coping and no interaction effects. Examining the relationship between hindrance stress and satisfaction, results suggest that there are main effects for maladaptive coping and hindrance stress but no interaction effects. Therefore, these findings indicate that there was not enough evidence to support Hypothesis 12.

The response for the employee snowball sample was not sufficient to test the moderation hypotheses. The survey link was sent to 3,106 employees who were referred by Florida International University undergraduate students. Of the referrals that were sent, more than ten percent of emails $(\mathrm{N}=364)$ were either invalid or incorrect and did not reach their intended recipients. Controlling for these invalid or incorrect emails, the response rate for the time one survey was 3.9 percent. Of the employees who participated in time one, only 33 percent successfully completed time two. The total response rate for the employee sample was about 1.3 percent $(\mathrm{N}=29)$. Given the low response rate and lack of power for interaction analyses, only correlation analyses were conducted (see Table 21 in the appendix for employee sample results).

\section{CHAPTER V - DISCUSSION}

The transactional model of stress appraisals posits that individuals consciously or unconsciously make a series of appraisals when experiencing a potentially stressful or threatening situation: 1) they decide whether the event is a threat or is taxing to resources, 
2) they determine whether what they are experiencing is positive or negative, and 3) they evaluate the most effective way to manage the situation. Complementing this theory, Cavanaugh and colleagues (2000) proposed the challenge-hindrance stressor theory that suggests that individuals recognize the potential reward associated with some stressful and taxing situations (i.e., challenges) and that they may also be subjected to stressful situations that have no positive outcomes (i.e., hindrances/hassles). Drawing upon both of these theories and the current literature that has examined individual differences in the appraisal process, the purpose of the current study was to develop and empirically test two separate models of stress. The primary goal of the current study was to investigate differences in organizational and individual outcomes in response to either challenge or hindrance stressors. By using the transactional conceptualization of stress appraisals in conjunction with the challenge-hindrance theory, the goal was also to specifically examine how certain domain-specific stressors may result in adaptive coping behaviors, whereas, other stressors might result in more maladaptive coping behaviors. The following sections will outline significant findings of the current study, implications for theory, practical applications, limitations, and future directions.

\section{Study Findings}

The first step in testing the models was to establish the relationship between stressor and coping styles. As expected, students experiencing a considerable amount of hindrance stress such as busy work in their classes or negative effects of professor favoritism tended to report more emotion-focused coping. Contrary to what was predicted, however, students who reported more challenge stress such as time pressure to meet class deadlines also tended to use more emotion-focused coping. In the challenge 
model of stressors, we predicted that there would be a negative relationship between stressor and emotion-focused coping because research has found that the cathartic nature of venting emotions does not necessarily reduce adverse effects of stressful emotions or situations (Bushman, Baumeister, \& Phillips, 2001). When dealing with hindrance stressors, it was predicted that there would be a positive relationship with emotionfocused coping because the student or employee would benefit from the sympathy or empathy of others when dealing with problems. Interestingly, these results suggest that students tend to respond to all stressors by venting their emotions or by seeking advice from others to manage the stressful situation. One possible explanation for this positive relationship might be that students utilize multiple coping mechanisms. For example, a student can be cognizant of the potential reward (e.g., class grade) associated with a challenge stressor (e.g., deadline to write a paper) and use problem-focused coping. Concurrently, the student might also attempt to counteract the negative aspect of time pressure by venting and using emotion-focused strategies.

In the challenge stress model, it was predicted that students reporting more challenge stress would utilize more problem-focused coping strategies such as planning or eliciting instrumental information from others because taking action to alleviate challenge stressors should be associated with potential benefits. The opposite relationship was predicted for the hindrance model of stress appraisal because students should not consciously perceive a reward for adopting a problem-focused strategy when experiencing hindrance stressors. Though derived from the theory, there was no relationship between students' self-reported challenge or hindrance stress and their predisposition to use problem-focused coping. Considering these relationships between 
stress and coping styles, these findings may suggest that coping strategies are independent, trait-based characteristics rather than variable state-based tendencies that are contingent upon environmental and situational influences. Another possible explanation for these non-significant findings could be related to the very measure of problemfocused coping. Perhaps participants' self-report responses for problem-focused coping were influenced by social desirability or because of the saliency of their school or work responsibilities. The positive direction of the correlation between hindrance stressor and problem-focused coping, though non-significant, might also indicate that the act of alleviating a hindrance is inherently rewarding. In other words, an employee or student may engage in problem-focused coping by filling out unnecessary paperwork, by completing busy work for classes, or by scheduling a meeting to address organizational policies with the reward being fewer stressors to manage later. There are a number of possibilities why the relationship between stressor and problem-focused coping were non-significant; likewise, there may be many other factors influencing the cognitive appraisal and decision-making process when an individual chooses to use problem solving or planning.

In the hindrance model of stress appraisals, it was predicted that students who experience a considerable amount of stress also reported being more behaviorally and mentally disengaged or avoidant. Contrary to what was hypothesized, however, students who are exposed to challenge stress were also more likely to cope by avoiding the stressful situation. Perhaps these findings are consistent for both challenge and hindrance stress because the implications for students who disengage to cope are not as severe as implications for employees. In other words, a student who behaviorally disengages by 
watching television rather than meeting a deadline for a paper may be able to get an extension by simply emailing the professor; however, an employee who fails to meet a deadline for an expense report or presentation might run the risk of being terminated. Furthermore, these findings might have been found for the student sample because the consequences for maladaptive coping are only on an individual level as opposed to an organizational level. Employees who choose disengage or use maladaptive coping, on the other hand, may also have a strong sense of organizational citizenship behavior and feel responsible for organizational outcomes.

Although the hypothesized relationships regarding coping behaviors were only partially supported and do not entirely fit the proposed challenge and hindrance models, it is important to mention significant findings for school satisfaction and performance. Students who reported experiencing more hindrance stress in the form of unclear class expectations, busy work, and general hassles at school were also significantly less satisfied with school. Interestingly, those students experiencing challenge stress did not report feeling significantly less satisfied with school. These findings may suggest that challenge stressors are more tolerable than hindrance stressors and, thus, do not adversely impact perceptions of school satisfaction. Furthermore, it is possible that students who experienced a significant amount of challenge stress might consciously or unconsciously have recognized the importance of these stressors. Regarding self-reported school performance, students who experienced more challenge stress such as time pressure, class responsibilities, and heavy workload also reported being high achievers in their classes. There was no significant relationship between students with high levels of hindrance stress and self-reported school performance. Similar to the findings for hindrance stress 
and satisfaction, these results may suggest that students are cognizant of the need for challenge stressors in their education and hindrance stressors as simply bothersome tasks that should not reflect their academic performance. In addition to self-reported performance, grade point average (GPA) was collected from students who provided consent to retrieve this information from their academic records. The amount of selfreported challenge stress did not significantly impact students' academic performance (GPA), but the attempt to triangulate these results by including self-report performance did not corroborate our hypotheses.

The aforementioned results present information regarding individual and organizational outcomes of stressors, but a secondary aim for the current study was to examine individual difference characteristics that might affect the utilization of certain coping strategies by students. It was predicted, for example, that motivation or personality characteristics such as self-efficacy act as a moderator between challenge and problem-focused coping. As previously mentioned, there was no relationship between students who experience challenge stress and their tendency to handle the stressor by attempting to alleviate it altogether (i.e., problem-focused coping). Core self-evaluations were tested as a moderator of the relationship between challenge stressor and problemfocused coping style. Results indicate that students scoring high (i.e., one standard deviation above the mean) on core self-evaluations used problem-focused coping more consistently than did students scoring low (i.e., one standard deviation below the mean) on core self-evaluations. It was hypothesized that the use of problem-solving strategies and planning would be more strongly related to self-report challenge stress for students scoring high on core self-evaluations than for students scoring low on core self- 
evaluations. Interestingly, students scoring low on core self-evaluations tended to use more problem-focused coping when challenge stress was high than students scoring high on core self-evaluations.

When investigating the role of core self-evaluations as a moderator of the relationship between hindrance stressor and problem-focused coping, results reflect similar trends that were seen in the challenge stressor moderated regression. Again, students scoring high on core self-evaluations displayed the propensity to use more problem-solving strategies, planning, and eliciting of instrumental information to alleviate the stressor. Typically, individuals who are less emotionally stable and who have low self-esteem, self-efficacy, and external locus of control are thought to be less capable of coping with stressors (Kammeyer-Mueller, et al., 2009). Although somewhat counterintuitive, these results suggest that these individuals use more productive coping mechanisms when exposed to greater amounts of stress in general. One possible explanation students scoring low on core self-evaluations were inclined to use more problem-solving strategies is because they ultimately wanted to alleviate the stressor. Despite feeling doubtful and having negative ideas about worth, the possibility for students with low core self-evaluations to elimination the stressor may be rewarding enough for them to actively employ problem-solving strategies.

In addition to testing core self-evaluations as a moderator of the relationship between stressor and problem-focused coping, the current study investigated the role of core self-evaluations in the relationship between stressor and emotion-focused coping. Challenge and hindrance stressors were significant predictors of a student's emotionfocused coping behavior; however, this relationship was not influenced by his or her level 
of core self-evaluations. This main effect, therefore, suggests that students scoring high or low on self-esteem, generalized self-efficacy, neuroticism, and locus of control typically vent of their emotions or seek advice from friends or family members when experiencing a stressful situation regardless of the type of stressor (i.e., challenge or hindrance). These findings do not support the hypotheses because it was expected that individuals scoring low on core self-evaluations would feel less capable of managing a stressful situation and, thus, benefit more from their venting of their emotions. Interestingly, core self-evaluations were not a significant predictor of emotion-focused coping as was seen by the non-significant main effect. This finding is somewhat surprising since the facets within the overarching construct of core self-evaluations are theoretically related to an individual's worldview and, therefore, should also be a predictor of whether they seek the sympathy or empathy from others in a stressful situation (Judge, 1997).

The possible moderating role of core self-evaluations was also examined with regard to relationship between stressor and maladaptive coping behavior. A student's level of challenge or hindrance stress did not significantly predict whether he or she would engage in more maladaptive coping strategies; therefore, the results do not support the hypothesized main effect for stressor type. It is intuitively appealing to expect an individual's level of self-reported stress (i.e., challenge or hindrance) to be predictive of whether he or she will become disengaged behaviorally or emotionally from his or her given situation, but the data do not support this supposition. Although stress was not a predictor of maladaptive coping, it is interesting to note that a student's core self evaluation score was a significant predictor of maladaptive coping. The finding that core 
self-evaluations predict maladaptive coping does support the predictions of the transactional stress models, in that, students with high generalized self-efficacy for example should theoretically engage in fewer behaviors because they feel that they are capable of managing the stressful event or situation. Core self-evaluations, though a significant predictor of maladaptive coping, did not moderate the relationship between stressor and coping style.

One aim of the current study was to examine individual differences as possible moderators of the stress-coping relationship, so in addition to core self-evaluations two types of motivation were also tested as moderators: extrinsic and intrinsic motivation. With regard to the relationship between challenge stressor and problem-focused coping, results suggest that students' level of self-reported extrinsic motivation (e.g., motivation for reward) was predictive of whether they were likely to use problem-focused coping strategies. The level of self-reported stress (challenge and hindrance), however, did not significantly predict whether a student reported problem-focused coping. Furthermore, extrinsic motivation did not influence the relationship between stress and problemfocused coping behavior; thus, students who scored high or low on extrinsic motivation were equally as likely to engage in problem-focused coping when faced with challenge or hindrance stressors. Theoretically speaking, those individuals who are highly motivated by reward and recognition should engage in more problem-solving or planning behavior when challenge stress is high because the reward for completing the challenge should be more salient for them, but this was not corroborated by the data. Though the reward is somewhat less salient for hindrance stressors, it was also predicted that individuals highly motivated by reward would engage in more problem-focused coping to mitigate the 
adverse effects of prolonged hindrance stressors, but again the results do not support this supposition. These findings for the moderated regression, therefore, do not provide support for extrinsic motivation as a moderator in neither the challenge nor the hindrance stress models.

Besides testing extrinsic motivation in the relationship between stressor and problem-focused coping, the role of extrinsic motivation in the relationship between stressor and emotion-focused coping was examined. As anticipated, both the level of selfreported challenge stress and level of extrinsic motivation were predictive of participants' emotion-focused coping behaviors. In other words, the amount of stress experienced by students related to meeting deadlines and completing relevant coursework as well as the importance a student places on rewards and recognition both influence whether they manage stress by seeking emotional support. While these findings provide initial support for the moderating effect of extrinsic motivation, the interaction between challenge stressor and extrinsic motivation was not a significant predictor of emotion-focused coping. Thus, students scoring high or low on extrinsic motivation when experiencing a challenge stressor tend to utilize emotion-focused coping strategies equally. As a whole, these results do not support the proposed interactions in the challenge model of stress appraisals. In the hindrance model, the results also indicate that a students' level of extrinsic motivation is predictive of emotion-focused coping behavior; however, the amount of reported hindrance stress was not predictive of whether a student would seek emotional support to cope with a given situation. Because hindrance stress within the school domain is related to busy work, ambiguous tasks, and unjust professor-student relationships (e.g., favoritism), it is surprising to think hindrance stress would not be 
predictive of emotion-focused coping. One might consider it fairly typical for an undergraduate student to complain about hindrance stressors to fellow students and perhaps their parents. As with the challenge model, these results do not fully support the proposed interactions.

When testing the proposed moderation of the relationship between stressor type and maladaptive coping, there was a significant main effect for challenge and hindrance stressor. The interaction suggests that the amount of stress that a student reports, regardless of the type, was predictive of maladaptive coping behavior, mental or behavioral disengagement. However, a student's level of extrinsic motivation was not predictive of the tendency to use maladaptive coping; thus, these findings suggest being driven by external rewards and recognition is not significantly related to negative forms of coping. On the basis of the theory of extrinsic and intrinsic motivation (Ryan \& Deci, 2000), one would expect individuals who are motivated by reward to be less likely to use an unproductive coping mechanism. Because extrinsic motivation was not predictive of maladaptive coping, the interaction between extrinsic motivation and stress was also not predictive of maladaptive coping. Therefore, these findings do not support the proposed challenge and hindrance models.

When examining the role of a student's intrinsic motivation on the relationship between his or her level of challenge stress and problem-focused coping, main effects were found for stressor and intrinsic motivation but no interaction. Therefore, these findings provide evidence to suggest that students' challenge stress can be used to predict their tendency to cope using problem-solving strategies. Furthermore, these results suggests that if a student derives motivation from the nature of a given task, then they 
will also engage in more proactive and adaptive coping strategies. However, the lack of interaction effects may indicate that students with either high or low levels of challenge stress tend to deal with it similarly, regardless of whether they tend to be motivated by the nature of a task or not. It was predicted that individuals experiencing high levels of challenge stress would recognize the inherent benefits associated with the stressor and, because they derive motivation from completing tasks, would engage in more planning and problem-solving behaviors. Although the main effect results suggest there is a relationship between stressor type and student motivation, overall these findings do not fully support the propositions outlined in the challenge transactional model.

The role of intrinsic motivation was also predicted to influence relationship between students' self-reported hindrance stress and problem-focused coping. The amount of hindrance stress reported by students in the form of hassles, busywork in classes, and professor favoritism was not predictive of problem-focused coping. Perhaps students were consciously or unconsciously aware of the fact that hindrance stressors do not provide the inherent benefits that are typically related to challenge stressors. As with the challenge model, however, intrinsic motivation was predictive of problem-focused coping strategies in the hindrance model. Therefore, it is possible to predict that students who tend to be motivated intrinsically by simply engaging in a given task will also be more proactive in dealing with stressful situations at school. There was also no significant interaction effects, so students who are driven to complete a task because of the nature of that task and students who are driven by other means (e.g., external factors, monetary incentives, or recognition) do not differ in whether they engage in more proactive, problem-focused coping behaviors. Given the theoretical underpinnings of these linkages, 
one might expect individuals motivated by internal mechanisms to engage in a relatively consistent amount of problem-solving or planning behavior when faced with positive or negative stressors because they derive some benefit from doing so. Conversely, one might predict that individuals who are not highly motivated by internal means would engage in more problem-focused behaviors when hindrance stress is low as opposed to when stress is high. Interestingly, the lack of significant interaction effects do not support these propositions and, therefore, do not provide evidence for the challenge transactional model.

Emotion-focused coping differs from problem-focused coping because it does not directly address the stressful or traumatic situation. As a result, as noted in the introduction, some researchers regard it as slightly less adaptive in workplace or school environments when students or employees utilize it as an exclusive form of coping. When used in tandem with problem-focused coping, however, utilizing emotion-focused strategies can be especially beneficial. In the current study, we examined the role of intrinsic motivation on the relationship between stressor type and emotion-focused coping. It was predicted that students who report being highly motivated by intrinsic means will engage in more emotion-focused coping behaviors when stress is high than students who report less motivation from intrinsic sources. The findings suggest that challenge and hindrance stressors are both predictors of emotion-focused coping, but intrinsic motivation was only a predictor of coping in the challenge transactional model. As one might expect, the amount of stress a student reported could be used to determine how likely they would vent of their emotions or seek social support from friends or family members. A possible explanation for why intrinsic motivation was not a predictor 
of coping in the hindrance model might be that because the stressor has no potential benefits, not even intrinsic benefits, we see no differentiation between students scoring high or low on intrinsic motivation. In both the challenge and hindrance models, there were no interaction effects and results do not correspond with the predicted relationships. On the basis of the proposed models and theoretical support, one would expect students who are not driven by internal factors would tend to engage in more emotion-focused coping behaviors when stress is high as compared students who are driven by internal factors. In other words, students who are not motivated by the nature of a task should seek more social support or choose to vent their emotions because the sympathy or empathy associated with emotion-focused coping might buffer the adverse effects of the stressor. When examining the data, however, these results do not support the proposed challenge or hindrance transactional models of stress appraisals.

While problem-focused and emotion-focused coping strategies have some benefits to an individual, maladaptive coping behaviors have fewer potential benefits. In the proposed models of stress appraisal, the influence of intrinsic motivation on the relationship between stressor type and maladaptive coping was investigated. For the challenge and hindrance models, individuals' levels of self-reported stress were predictive of whether they tended to engage in maladaptive behavior; students with more stress regardless of the type were more likely to be behaviorally or mentally disengaged. In both the challenge and hindrance models, if a student reported being more intrinsically motivated, then they were significantly less likely to engage in maladaptive coping behaviors. There were no significant interaction effects, so students reporting either high 
or low stress were equally likely to engage in maladaptive coping behavior and intrinsic motivation did not significantly influence this relationship.

Intuitively, and according to theory, it was predicted that coping behavior would influence the relationship between stressor type and self-reported domain satisfaction. Specifically, for example, a student who uses more problem-solving strategies to cope with challenge stressors such as time pressure to meet class deadlines should be alleviating the source of stress and, therefore, report greater school satisfaction than a student who did not employ this coping strategy. The results suggest that problemfocused coping acts as a predictor of school satisfaction, but there was no main effect for challenge stress. In other words, the number of class assignments, project deadlines, or amount of student responsibility did not significantly influence whether a student was satisfied with school or not. These findings are somewhat counterintuitive because this suggests that other factors, perhaps not directly related to coursework, were influencing students' perceptions of satisfaction. In addition to problem-focused coping behavior, it was predicted that emotion-focused coping would influence the relationship between stressor type and coping. The findings from this analysis suggest that neither coping behavior nor challenge stress were predictors of school satisfaction. School and job satisfaction are typically associated with an affective response to internal or external domain factors; for example, an employee might report lower satisfaction because they experience interpersonal conflict. One possible reason seeking social support to deal with stressors was not related to school satisfaction may be because doing so makes the negative events more salient to students. In fact, literature examining employee preference for work-family integration versus segmentation has touched upon the benefits 
and problems associated with blending school, work, and family domains (Ashforth, Kreiner, \& Fugate, 2000). For the role of maladaptive coping behaviors, it was hypothesized that students who report more behavioral or mental disengagement would report less school satisfaction when challenge stress was high. The results suggest that maladaptive coping was a negative predictor of school satisfaction. Therefore, students reporting more mental and behavioral disengagement tended to be less satisfied with school. As with the other analyses, the amount of challenge stress experienced by students was not related to whether they had positive or negative perceptions of school satisfaction. Collectively, coping behavior did not act as a buffer in the relationship between students' self-reported challenge stress and perceptions of school satisfaction, thus, not providing support for the proposed challenge transactional model.

In the hindrance model of stress, the role of coping behaviors on the relationship between student's hindrance stress and school satisfaction were examined. In all three moderated regression analyses, students' level of hindrance stress in the form of unclear class objectives, unjust professor favoritism, or general class hassles was predictive of lower school satisfaction. With regard to problem-focused coping, whether a student tended to deal with stressors by utilizing problem-solving or planning strategies was predictive of higher of school satisfaction. Conversely, maladaptive coping behaviors were predictive of lower levels of self-reported school satisfaction. The amount of emotion-focused coping used by students in the form of venting or seeking social support did not significantly influence perceptions of school satisfaction. Although there were a number of significant main effect findings, the non-significant interactions suggest that 
coping behavior did not buffer the relationship between hindrance stressor and school satisfaction.

While one might expect coping to buffer the negative effects of stress on perceptions of satisfaction, it is also reasonable to think that coping behaviors might influence the relationship between stress and performance. For the challenge transactional model, results suggest that students' level of problem-focused coping helped in determining their self-report school performance in the positive direction and maladaptive coping was predictive of performance in the negative direction; however, emotion-focused coping was not related to school performance. Challenge stress was not a significant predictor of how students responded to self-report school performance, except in the maladaptive coping moderation analysis. These findings indicate that regardless of the type of strategy, coping did not moderate the relationship between stressor and self-reported performance. The buffering effect that was hypothesized, whereby students who utilize coping behaviors would report greater school performance, was not supported. There are certain criticisms and limitations related to self-report performance, so the same moderation analyses were conducted using student GPA. Interestingly, the only significant main effect was for emotion-focused coping. This main effect suggests that whether a student engaged in venting or seeking social support was predictive of academic performance and was reflected in GPA. The lack of interaction effects using both self-report and GPA as measures of academic performance do not provide evidence for the proposed relationships in the challenge transactional model.

When examining the role of coping behaviors on the relationship between hindrance stress and school performance, the results from the self-reported performance 
measure suggest that problem-focused, emotion-focused, and maladaptive coping were all significant predictors. In other words, in the three separate moderated regressions, students who engaged in more problem-focused and emotion-focused coping were more likely to report doing well in their classes and students who used maladaptive coping were less likely to report strong academic performance. The amount of hindrance stress a student experienced in the form of ambiguous tasks or hassles did not significantly impact his or her perception of school performance, except in the maladaptive coping regression. With GPA as the outcome variable, there were no main effects for coping or stress. It is possible that the discrepancy between self-reported academic performance and a more objective measure (i.e., GPA) exists because academic performance involves a number of factors. In the workplace, for example, a sales associate's performance might be measured by factors such as interpersonal relationships or undertaking leadership roles and simply examining sales or commission might not provide an accurate portrayal of his or her performance. When using self-report or GPA as the academic performance measure, however, coping strategies did not moderate the relationship between hindrance stress and performance; the hypothesized buffering effect of coping on stress was not present. Therefore, students who tended to use more coping strategies were not necessarily more productive when experiencing highly stressful situations as compared to students who did not tend to use coping strategies. Although on the whole these findings do not support the proposed models, they certainly provide some significant implications for theory and future stress-related research. Theoretical and Practical Implications 
The challenge-hindrance model of stress was founded on the idea that some stressors have potential rewards associated with them, while other stressors do not come with any benefits (Cavanaugh, et al., 2000). Collectively, the current data did not provide much evidence to support the challenge-hindrance theory. In fact, the only differences were found in the relationships between stressor type, school performance, and school satisfaction. It is possible that stressors are appraised as challenges or hindrances; however, perceptions of what situations are positive or beneficial may differ for each individual. For example, a time demand to meet a deadline might be particularly negative for an individual who experiences a significant amount of anxiety when projects are unfinished. In this type of situation, the negative stress and anxiety may consume the individual and, thus, render them unable to see the potential benefit. Another theoretical implication of these findings can be drawn from the literature investigating work-life boundaries (Ashforth, Kreiner, \& Fugate, 2000). Individuals who choose to compartmentalize school and work domains may be protected against the adverse effects of hindrance stressors. Overall, there was little support for the challenge-hindrance framework; perhaps the cognitive appraisal models proposed failed to account for anticipated amounts of stress. For example, participants may have recognized stress as a normal part of being a student and only experienced a decline in academic performance or satisfaction when stress exceeded those perceptions of normal (e.g., Schwarzer, 2004).

In an attempt to integrate findings from current literature, it was hypothesized that motivation and personality in the form of core self-evaluations would moderate the relationship between stress and coping behavior. As mentioned previously, there are cognitive processes that occur when appraising stressful situations. No previous models 
or theories have looked at motivation orientation or core self-evaluations as individual differences in stress appraisals. In the current model, it was predicted on the basis of the challenge-hindrance theory that reward would be more salient for extrinsically motivated individuals and, therefore, they would use more coping for challenge stressors than nonextrinsically motivated individuals. It is possible that non-significant interactions indicate that coping strategies are, as theorized by Folkman, Lazarus et al. (1986), trait-oriented and not usually influenced by external factors.

Stress has certainly been found to negatively impact perceptions of satisfaction and performance; the literature has supported this assumption in many empirical instances (Podsakoff, et al., 2007). Perhaps the model of cognitive stress appraisals did not account for the possibility that coping does not mitigate the negative effects of stress; rather, it might make the individual more resilient and less susceptible to stressors. If this were the case, regardless of the type of stressor (i.e., challenge or hindrance), participants might have reported overall lower stress despite having potentially the same number of stressful experiences as less resilient participants. In accordance with this supposition, scores on the overarching construct of core self-evaluations were negatively related to both types of stressors. Though these relationships are simply correlations and causation cannot be drawn from them, it is interesting to note that students with a more positive self-image tended to report less stress overall. In addition to these individual differences in self-reported stress, none of the moderated regression analyses were significant for the three coping styles and in many instances stress was not a predictor of performance or satisfaction, so these findings somewhat contradict previous theories about coping in a school or work environment. 
From a more practical perspective, these non-significant findings suggest that an individual who utilizes coping strategies will not always be better equipped to deal with stressful school or work situations. Therefore, developers of stress management programs should always evaluate the effectiveness of the strategies they are teaching and provide students or employees with multiple alternative ways to deal with stressors. For educators and managers, it was found that challenge stress was positively related to performance, so providing students or employees with responsibility, clear objectives, and deadlines can increase self-reported performance. Moreover, hindrance stress was negatively related to school satisfaction, so professors and managers should attempt to minimize unnecessary hassles, red tape, and unjust favoritism. Although there were no interaction effects for motivation orientation as a moderator of the relationship between stressor type and coping behavior, it is important to note the strong correlations between motivation orientation and stress. When applying these findings to the school environment, they suggest that students are driven by monetary reward also tend to report more stress overall; whereas, students who are motivated by the nature of the job report significantly less stress. Recognizing these potential pitfalls as a professor or manager, therefore, may be helpful when managing student or employee performance, if findings generalize across samples.

Limitations and Future Directions

After testing the various model linkages, it became evident that many of the predicted relationships were non-significant. In the previous section, the implications on theory and practice were discussed; however, it is essential to evaluate possible limitations of the method, scales, and model design. One limitation of the current study 
was that only self-reported data were collected from student and employee samples, with the exception of student GPA. As many researchers have found, responses on self-report measures are sometimes fraught with problems: social desirability, memory effects, and unreliability of recall (Crockett, Schulenberg, \& Petersen, 1987; Cronbach, 1970). Though precautions to reduce response distortion were taken (i.e., anonymity of participants, responses were not linked to work performance or grades, etc.), it is possible that students and employees wanted to appear more socially acceptable. Future studies of student and employee stress, personality, and coping might benefit from including more objective measures. In the case of stress, for example, research would benefit from interdisciplinary research measuring the biological stress indicators such as high blood pressure, increased heart rate, perspiration, decreased glucose levels, and elevated cortical levels and cognitive appraisals of stressors (Cohen, Kessler, \& Gordon, 1997). Additionally, future studies of stress models should consider using supervisory ratings of employee performance as a more objective measure or spouse/significant other ratings of student or employee satisfaction. Another limitation of the current study, related to selfreport data, was that there seemed to be a large discrepancy between student's self-report academic performance and GPA. One would anticipate there to be a moderate to strong correlation; however, that was not observed in the student sample. One explanation for this limitation could be that there was range restriction since GPA was only accessible for students majoring in psychology and not the entire sample.

Unfortunately, the employee snowball sample did not yield enough participants to draw meaningful results or to conduct interaction analyses. Efforts were taken to recruit employees and over 3,100 emails were sent; perhaps the low response rate was because 
there were no incentives for the employees. This significantly limits the generalizability of findings to organizational and employee samples. The stressors experienced by students may be somewhat different from those experienced by employees and the strategies utilized to cope with them may differ for employees because of contextual factors. Students, for example, are mainly responsible for their own success in their classes, whereas, employees in work groups or teams share task responsibility. A future direction for stress and coping research and model development should include or control for contextual factors. Furthermore, the field would benefit significantly from more multilevel and team level analysis of stress.

One aim of the current model of stress appraisals was to determine if coping style could buffer the adverse effects of stress on domain performance and satisfaction. In all of the separate analyses, the interactions effects were non-significant. Therefore, there is a need for additional research to answer the question, "In what instance does coping buffer the relationship between stress and organizational or academic outcomes?" This avenue of research may have important implications on organizational and academic interventions. In the employee-training realm, for example, a stress management trainer could develop programs according to which coping mechanism will best alleviate the stressor and, thus, lead to more productivity and job satisfaction. This paradigm of research is also closely related to the positive psychology construct of resiliency. Future researchers might also consider including a resiliency scale to better establish the linkages between stressor, coping, performance, and satisfaction. Concluding Remarks 
The primary aim of this thesis was to integrate the existing literature into a testable, comprehensive model to provide a greater understanding of the cognitive appraisal process of stressors. The challenge-hindrance framework was used for the current study along with individual differences measures of motivation and core selfevaluations. Overall, the results did not provide evidence for the integration of the challenge-hindrance framework with the transactional appraisal model of stress. Although there was not adequate evidence supporting the challenge and hindrance models, the findings do provide information pertaining to the cognitive processing of stressors in general. The most notable finding was that core self-evaluations moderated the relationship between challenge stressor and problem-focused coping and that core self-evaluations also moderate the relationship between hindrance stressor and problemfocused coping. 


\section{LIST OF REFERENCES}

Aiken, L. S. \& West, S. G. (1991). Multiple regression: Testing and interpreting interactions. Thousand Oaks, CA: Sage Publications, Inc.

Amabile, T. M., Hill, K. G., Hennessey, B. A., \& Tighe, E. M. (1994). The work preference inventory: Assessing intrinsic and extrinsic motivation orientations. Journal of Personality and Social Psychology, 66, 950-967.

Ashforth, B. E., Kreiner, G. E., \& Fugate, M. (2000). All in a day's work: Boundaries and micro-role transitions. Academy of Management Review, 25, 472-491.

Bhagat, R. S., Allie, S. M., \& Ford, D. L. (1991). Organizational stress, personal life stress and symptoms of life strains: An inquiry into the moderating role of styles of coping. Journal of Social Behavior and Personality, 6, 163-184.

Billings, A. G., \& Moos, R. H. (1984). Coping, stress, and social resources among adults with unipolar depression. Journal of Personality and Social Psychology, 46, 877891.

Boyd, N. G., Lewin, J. E., \& Sager, J. K. (in press). A model of stress and coping and their influence on individual and organizational outcomes. Journal of Vocational Behavior. doi:10.1016/j.jvb.2009.03.010

Brown, S. P., Westbrook, R. A., \& Challagalla, G. (2005). Good cope, bad cope: Adaptive and maladaptive coping strategies following a critical negative work event. Journal of Applied Psychology, 90, 792-798. doi: 10.1037/00219010.90.4.792

Brunner, L. \& Colarelli, S. M. (2004). Individual unemployment accounts. The Independent Review, 8, 569-585. doi: 1086-1653

Bushman, B. J., Baumeister, R. F., \& Phillips, C. M. (2001). Do people aggress to improve their mood? Catharsis beliefs, affect regulation opportunity, and aggressive responding. Journal of Personality and Social Psychology, 81, 17-32. 
Butler, A. B. (2007). Job characteristics and college performance and attitudes: A model of work-school conflict and facilitation. Journal of Applied Psychology, 92, 500510. doi: 10.1037/0021-9010.92.2.500

Carlson, D. S., \& Perrewe, P. L. (1999). The role of social support in the stressor-strain relationship: An examination of work-family conflict. Journal of Management, $25,513-540$.

Carver, C. S., Scheier, M. F., \& Weintraub, J. K. (1989). Assessing coping strategies: A theoretically based approach. Journal of Personality and Social Psychology, 56, 276-283.

Cavanaugh, M. A., Boswell, W. C., Roehling, M. V., \& Boudreau, J. W. (2000). An empirical examination of self-reported work stress among U.S. managers. Journal of Applied Psychology, 85, 65-74.

Cohen, J., \& Cohen, P. (1983). Applied multiple regression/correlation analysis for the behavioral sciences (2nd ed.). Hillsdale, NJ: Erlbaum.

Cohen, S., Kessler, R. C., \& Gordon, L. U. (1997). Strategies for measuring stress in studies of psychiatric and physical disorders. In Measuring Stress: A Guide for Health and Social Scientists. New York: Oxford University Press.

Costa, P. T., \& McCrae, R. R. (1984). Influence of extroversion and neuroticism on subjective well-being: Happy and unhappy people. Journal of Personality and Social Psychology, 38, 668-678.

Costa, P. T., \& McCrae, R. R. (1990). Personality: Another "hidden factor" in stress research. Psychological Inquiry, 1, 22-24.

Coyne, J. C., Aldwin, C., \& Lazarus, R. S. (1981). Depression and coping in stressful episodes. Journal of Abnormal Psychology, 90, 439-447.

Crockett, L.T., Schulenberg, J. E., \& Petersen, A. C. (1987). Congruence between objective and self-report data in a sample of young adolescents. Journal of Adolescent Research, 2, 383-392.

Cronbach, L. J. (1970). Essential of Psychological Testing (3 ${ }^{\text {rd }}$ Edition). New York: Harper \& Row.

Deci, E. L., \& Ryan, R. M. (1985). The general causality orientations scale: Selfdetermination in personality. Journal of Research in Personality, 19, 109-134.

Fogarty, G. J., Machin, M. A., Albion, M. J., Sutherland, L. F., Lalor, G. I., \& Revitt, S. (1999). Predicting occupational strain and job satisfaction: The role of stress, 
coping, personality, and affectivity variables. Journal of Vocational Behavior, 54, 429-452. 0001-8791/99

Fiske, D. W. (1980). When are verbal reports veridical? New Directions for Methodology of Social Behavioral Sciences, 4, 59-67.

Folkman, S., \& Lazarus, R. S. (1986). Stress processes and depressive symptomatology. Journal of Abnormal Psychology, 95, 107-113. doi: 002I-843X/86/

Folkman, S., Lazarus, R. S., Dunkel-Schetter, C., DeLongis, A., \& Gruen, R. J. (1986). Dynamics of a stressful encounter: Cognitive appraisal, coping, and encounter outcomes. Journal of Personality and Social Psychology, 50, 992-1003. 0022$3514 / 86 /$

Folkman, S., Lazarus, R. S., Gruen, R. J., \& DeLongis, A. (1986). Appraisal, coping, health status, and psychological symptoms. Journal of Personality and Social Psychology, 50, 571-579. doi: 0022-3514/86/

Gilboa, S., Shirom, A., Fried, Y., \& Cooper, C. (2008). A meta-analysis of work demand stressors and job performance: Examining main and moderating effects. Personnel Psychology, 61, 227-271.

Gordon, M. E., Slade, L. A., \& Schmitt, N. (1986). The "Science of the Sophomore" revisited: from conjecture to empiricism. Academy of Management Review, 11, 191-207.

Greenberg, J. (1987). The college sophomore as guinea pig: Setting the record straight. The Academy of Management Review, 12, 157-159.

Hackman, R. J. \& Oldham, G. R. (1975). Development of the job diagnostic survey. Journal of Applied Psychology, 60 (2), 159-170.

Harris, K. J., Harvey, P., \& Kacmar, K. M. (2009). Do social stressors impact everyone equally? An examination of the moderating impact of core self-evaluations. Journal of Business Psychology, 24, 153-164.

Hobfoll, S. E. (1989). Conservation of resources. American Psychologist, 44, 513-524. Jex, S. M. (1998). Stress and job performance: Theory, research, and implications for managerial practice. Thousand Oaks, CA: Sage Publications.

Jex, S. M., Bliese, P. D., Buzzell, S., \& Primeau, J. (2001). The impact of self-efficacy on stressor-strain relations: Coping style as an explanatory mechanism. Journal of Applied Psychology, 86, 401-409. doi: 10.I037//0021-90I0.86.3.401 
Judge, T. A. Locke, E. A., \& Durham, C. C. (1997). The dispositional causes of job satisfaction: A core self-evaluations approach. Research in Organizational Behavior, 19, 151-188.

Judge, T. A., Erez, A., Bono, J. E., \& Thoresen, C. J. (2003). The core self-evaluation scale: Development of a measure. Personnel Psychology, 56, 303-331.

Kammeyer-Mueller, J. D., Judge, T. A., \& Scott, B. A. (2009). The role of core selfevaluations in the coping process. Journal of Applied Psychology, 74, 177-196. doi: $10.1037 / \mathrm{a} 0013214$

Lam, C. F., \& Gurland, S. T. (2008). Self-determined work motivation predicts job outcomes, but what predicts self-determined work motivation? Journal of Research in Personality, 42, 1109-1115. doi:10.1016/j.jrp.2008.02.002

Lazarus, R. S., \& Folkman, S. (1984). Stress, appraisal, and coping. New York: Springer.

Leonard, N. H., Beauvais, L. L. \& Scholl, R. W. (1999). Work motivation: The incorporation of self-concept-based processes. Human Relations, 52, 969-998. doi: 0018-7267/99/0800-0969

LePine, J. A., LePine, M. A., \& Jackson, C. L. (2004). Challenge and hindrance stress: Relationship with exhaustion, motivation to learn, and learning performance. Journal of Applied Psychology, 89, 883-891. doi: 10.1037/0021-9010.89.5.883

LePine, J. A., Podsakoff, N. P., \& LePine, M. A. (2005). A meta-analytic test of the challenging stressor-hindrance stressor framework: An explanation for inconsistent relationships among stressors and performance. Academy of Management Journal, 48, 764-775.

Li, M., \& Yang, Y. (2009). Determinants of problem-solving, social support seeking, and avoidance: A path analytic model. International Journal of Stress Management, 16, 155-176. doi: 10.1037/a0016844

Mantler, J., Matejicek, A., Matheson, K., \& Anisman, H. (2005). Coping with unemployment uncertainty: A comparison of employed and unemployed workers. Journal of Occupational Health Psychology, 10, 200-209. doi: 10.1037/10768998.10.3.200

Markel, K. S., \& Frone, M. R. (1998). Job characteristics, work-school conflict, and school outcomes among adolescents: Testing a structural model. Journal of Applied Psychology, 83, 277-287. 
McClelland, G. H. \& Judd, C. M. (1993). Statistical difficulties of detecting interactions and moderator effects. Psychological Bulletin, 114, 376-390. doi: 10.1037?00332909.114.2.376

Moneta, G. B. \& Spada, M. M. (2009). Coping as a moderator of the relationship between trait intrinsic and extrinsic motivation and approaches to studying during academic exam preparation. Personality and Individual Differences, 46, 664-669. doi:10.1016/j.paid.2009.01.012

Parkes, K. R. (1990). Coping, negative affectivity, and the work environment: Additive and interactive predictors of mental health. Journal of Applied Psychology, 75, 399-409. doi: 0021-90IO/90/

Pearlin, L. I., \& Schooler, C. (1978). The structure of coping. Journal of Health and Social Behavior, 19, 2-21.

Pearsall, M. J., Ellis, A. P. J., \& Steinm J. H. (2009). Coping with challenge and hindrance stressors in teams: Behavioral, cognitive, and affective outcomes. Organizational Behavior and Human Decision Processes, 109, 18-28. doi:10.1016/j.obhdp.2009.02.002

Peterson, R. A. (2001). On the use of college students in social science research: Insights from a second-order meta-analysis. Journal of Consumer Research, 28, 450-461.

Podsakoff, N. P., LePine, J. A., \& LePine, M. A. (2007). Differential challenge stressorhindrance stressor relationships with job attitudes, turnover intentions, turnover, and withdrawal behavior: A meta-analysis. Journal of Applied Psychology, 92, 435-454. doi: 10.1037/0021-9010.92.2.438

Richer, S. F., Blanchard, C., \& Vallerand, R. J. (2002). A motivational model of turnover. Journal of Applied Social Psychology, 32, 2089-2113.

Rosenberg, M. (1979). Conceiving the self. New York, NY: Basic Books.

Rotter, J. B. (1966). Generalized expectancies for internal versus external control of reinforcement. Psychological Monographs, 80, 1-28.

Ryan, R. M. \& Deci, E. L. (2000). Self-determination theory and the facilitation of intrinsic motivation, social development, and well-being. American Psychologist, $55,68-78$.

Saunders, D. R. (1956). Moderator variables in prediction. Educational and Psychological Measurement, 16, 209-222. doi: 10.1177/001316445601600205 
Schaubroeck, J. (1999). Should the subjective be the objective? On studying mental processes, coping behavior, and actual exposure in organizational stress research. Journal of Organizational Behavior, 20, 753-760. doi: 0894-3796/99/050753-08

Schwarzer, R. (2004). Managing stress at work through preventive and proactive coping. In E. A. Locke (Ed.). Handbook of Principles of Organizational Behavior. Malden, MA: Blackwell Publishing.

Selye, H. (1982). History and present status of the stress concept. In L.Goldberger \& S. Breznitz (Eds.), Handbook of stress. NewYork: Free Press.

Sonnentag, S., \& Frese, M. (2003). Stress in organizations. In I. B. Weiner (Ed.). Handbook of Psychology, Volume Twelve: Industrial Organizational Psychology. Hoboken, NJ: John Wiley and Sons, Inc.

Spector, P. E. (1982). Behavior in organizations as a function of employee's locus of control. Psychological Bulletin, 91, 482-497. doi: 0033-2909/82/9103-0482/

Stetz, T. A., Stetz, M. C., \& Bliese, P. D. (2006). The importance of self-efficacy in the moderating effects of social support on stressor-strain relationships. Work and Stress, 20, 49-59. doi: 10.1080/02678370600624039

Van Dyne, L., \& LePine, J. (1998). Helping and voice extra-role behaviors: Evidence of construct and predictive validity. Academy of Management Journal, 41, 108-119.

Welbourne, J. L., Eggerth, D., Hartley, T. A., Andrew, M. A., \& Sanchez, F. (2007). Coping strategies in the workplace: Relationships with attributional style and job satisfaction. Journal of Vocational Behavior, 70, 312-325. doi:10.1016/j.jvb.2006.10.006

Weiss, H. M., \& Cropanzano, R. (1996). Affective events theory: A theoretical discussion of the structure, causes and consequences of affective experiences at work. In B. M. Staw \& L. L. Cummings (Eds.). Research in organizational behavior. Greenwich, CT: JAI Press.

Zedeck, S. (1971). Problems with the use of "moderator" variables. Psychological Bulletin, 76, 295-310. doi: 10.1037/h0031543 


\section{APPRENDIX A - Tables}

Table 1. Correlations, Means, Standard Deviations, and Reliabilities for Students

\begin{tabular}{|c|c|c|c|c|c|c|c|c|c|c|c|c|c|}
\hline Variable & $M$ & $S D$ & 1 & 2 & 3 & 4 & 5 & 6 & 7 & 8 & 9 & 10 & 11 \\
\hline 1. Challenge Stress & 3.51 & 1.00 & $(.94)$ & & & & & & & & & & \\
\hline 2. Hindrance Stress & 2.93 & .91 & $.71^{* * *}$ & (.84) & & & & & & & & & \\
\hline 3. CSES & 5.19 & 1.02 & $-.32^{* * *}$ & $-.48^{* * *}$ & $(.82)$ & & & & & & & & \\
\hline 4. Intrinsic Motivation & 2.98 & .35 & $-.12^{*}$ & $-.10^{*}$ & $.22^{* * *}$ & $(.79)$ & & & & & & & \\
\hline 5. Extrinsic Motivation & 2.70 & .38 & $.23^{* * *}$ & $.21^{* * *}$ & .07 & $.10^{*}$ & $(.66)$ & & & & & & \\
\hline 6. Problem-Focused & 2.91 & .48 & .06 & .04 & $.17^{* * *}$ & $.34^{* * *}$ & $.27^{* * *}$ & $(.90)$ & & & & & \\
\hline 7. Emotion-Focused & 2.61 & .76 & $.18^{* * *}$ & $.27^{* * *}$ & .00 & .07 & $.31^{* * *}$ & $.33^{* * *}$ & $(.90)$ & & & & \\
\hline 8. Maladaptive & 1.98 & .61 & $.18^{* * *}$ & $.27^{* * *}$ & $-.41^{* * *}$ & $-.16^{* * *}$ & $.11^{* *}$ & -.07 & $.23^{* * *}$ & $(.85)$ & & & \\
\hline 9. Satisfaction & 3.90 & .76 & -.04 & $-.13^{* *}$ & $.25^{* * *}$ & $.21^{* * *}$ & $.13^{* *}$ & $.20^{* * *}$ & .03 & $-.14^{* *}$ & $(.93)$ & & \\
\hline 10. Performance & 4.05 & .64 & $.09 *$ & .01 & $.21^{* * *}$ & $.17^{* * *}$ & $.20^{* * *}$ & $.22^{* * *}$ & $.09^{*}$ & $-.19^{* * *}$ & $.20^{* * *}$ & $(.71)$ & \\
\hline 11. GPA & 2.90 & 1.04 & .05 & -.07 & .11 & .01 & $.15^{*}$ & .03 & $.16^{*}$ & .01 & -.09 & .01 & $N / A$ \\
\hline
\end{tabular}

Note. Internal consistency reliabilities $(\alpha)$ estimates are reported on the diagonal. $\mathrm{N}$ for all reported correlations was 538 with the exception of GPA $(\mathrm{N}=184) * p<.05 * * p<.01 * * * p<.001$ 
Table 2. Moderated Regression for CSE, Challenge Stress, and Coping

\begin{tabular}{|c|c|c|c|c|c|c|}
\hline & \multicolumn{2}{|c|}{ Problem-Focused } & \multicolumn{2}{|c|}{ Emotion-Focused } & \multicolumn{2}{|c|}{ Maladaptive } \\
\hline & $\beta$ & $\Delta \mathrm{R}^{2}$ & $\beta$ & $\Delta \mathrm{R}^{2}$ & $\beta$ & $\Delta \mathrm{R}^{2}$ \\
\hline \multicolumn{7}{|l|}{ Step One } \\
\hline Challenge Stress $\left(\mathrm{A}_{1}\right)$ & $.13^{* *}$ & .045 & .06 & .037 & $-.39^{* * *}$ & .172 \\
\hline Core Self-Evaluation (B) & $.21^{* * *}$ & & $.20^{* * *}$ & & .06 & \\
\hline \multicolumn{7}{|l|}{ Step Two } \\
\hline Challenge Stress $\left(\mathrm{A}_{1}\right)$ & $.14^{* *}$ & .008 & .06 & .001 & $-.39^{* * *}$ & \\
\hline Core Self-Evaluation (B) & $.22^{* * *}$ & & $.20^{* * *}$ & & .06 & \\
\hline $\mathrm{A}_{1} \times \mathrm{B}$ & $-.09^{*}$ & & .03 & & -.02 & \\
\hline
\end{tabular}

Note. ${ }^{*} p<.05 * * p<.01 * * * p<.001$ 
Table 3. Moderated Regression for CSE, Hindrance Stress, and Coping

\begin{tabular}{|c|c|c|c|c|c|c|}
\hline & \multicolumn{2}{|c|}{ Problem-Focused } & \multicolumn{2}{|c|}{ Emotion-Focused } & \multicolumn{2}{|c|}{ Maladaptive } \\
\hline & $\beta$ & $\Delta \mathrm{R}^{2}$ & $\beta$ & $\Delta \mathrm{R}^{2}$ & $\beta$ & $\Delta \mathrm{R}^{2}$ \\
\hline \multicolumn{7}{|l|}{ Step One } \\
\hline Hindrance Stress $\left(\mathrm{A}_{2}\right)$ & $.25^{* * *}$ & .048 & $.14^{* *}$ & .014 & $.10^{*}$ & .177 \\
\hline Core Self-Evaluation (B) & $.16^{* * *}$ & & .06 & & $-.36^{* * *}$ & \\
\hline \multicolumn{7}{|l|}{ Step Two } \\
\hline Hindrance Stress $\left(\mathrm{A}_{2}\right)$ & $.26^{* * *}$ & .011 & $.14^{* *}$ & .000 & $.10^{*}$ & .000 \\
\hline Core Self-Evaluation (B) & $.15^{* * *}$ & & .06 & & $-.36^{* * *}$ & \\
\hline $\mathrm{A}_{2} \mathrm{XB}$ & $-.13^{* *}$ & & .01 & & -.01 & \\
\hline
\end{tabular}

Note. $* p<.05 * * p<.01 * * * p<.001$ 
Table 4. Moderated Regression for Extrinsic Motivation, Challenge Stress, and Coping

\begin{tabular}{|c|c|c|c|c|c|c|}
\hline & \multicolumn{2}{|c|}{ Problem-Focused } & \multicolumn{2}{|c|}{ Emotion-Focused } & \multicolumn{2}{|c|}{ Maladaptive } \\
\hline & $\beta$ & $\Delta \mathrm{R}^{2}$ & $\beta$ & $\Delta \mathrm{R}^{2}$ & $\beta$ & $\Delta \mathrm{R}^{2}$ \\
\hline \multicolumn{7}{|l|}{ Step One } \\
\hline Challenge Stress $\left(\mathrm{A}_{1}\right)$ & .00 & .068 & $.12^{* *}$ & .109 & .17 & .038 \\
\hline Extrinsic Motivation (B) & $.27^{* * *}$ & & $.28^{* * *}$ & & .07 & \\
\hline \multicolumn{7}{|l|}{ Step Two } \\
\hline Challenge Stress $\left(\mathrm{A}_{1}\right)$ & .00 & .002 & $.11^{* *}$ & .006 & .16 & .000 \\
\hline Extrinsic Motivation (B) & $.27^{* * *}$ & & $.28^{* * *}$ & & .07 & \\
\hline $\mathrm{A}_{1} \mathrm{XB}$ & -.01 & & -.08 & & .00 & \\
\hline
\end{tabular}

Note. ${ }^{*} p<.05 * * p<.01 * * * p<.001$

Table 5. Moderated Regression for Extrinsic Motivation, Hindrance Stress, and Coping 


\begin{tabular}{|c|c|c|c|c|c|c|}
\hline & \multicolumn{2}{|c|}{ Problem-Focused } & \multicolumn{2}{|c|}{ Emotion-Focused } & \multicolumn{2}{|c|}{ Maladaptive } \\
\hline & $\beta$ & $\Delta \mathrm{R}^{2}$ & $\beta$ & $\Delta \mathrm{R}^{2}$ & $\beta$ & $\Delta \mathrm{R}^{2}$ \\
\hline \multicolumn{7}{|l|}{ Step One } \\
\hline Hindrance Stress $\left(\mathrm{A}_{2}\right)$ & -.02 & .071 & .04 & .098 & $.26^{* * *}$ & .078 \\
\hline Extrinsic Motivation (B) & $.27^{* * *}$ & & $.30^{* * *}$ & & .06 & \\
\hline \multicolumn{7}{|l|}{ Step Two } \\
\hline Hindrance Stress $\left(A_{2}\right)$ & -.02 & .001 & .05 & .002 & $.26^{* * *}$ & .001 \\
\hline Extrinsic Motivation (B) & $.27^{* * *}$ & & $.30^{* * *}$ & & .06 & \\
\hline $\mathrm{A}_{2} \mathrm{X} \mathrm{B}$ & .02 & & & & & \\
\hline
\end{tabular}

Note. $* p<.05 * * p<.01 * * * p<.001$ 


\begin{tabular}{|c|c|c|c|c|c|c|}
\hline & \multicolumn{2}{|c|}{ Problem-Focused } & \multicolumn{2}{|c|}{ Emotion-Focused } & \multicolumn{2}{|c|}{ Maladaptive } \\
\hline & $\beta$ & $\Delta \mathrm{R}^{2}$ & $\beta$ & $\Delta \mathrm{R}^{2}$ & $\beta$ & $\Delta \mathrm{R}^{2}$ \\
\hline \multicolumn{7}{|l|}{ Step One } \\
\hline Challenge Stress $\left(A_{1}\right)$ & $.10^{*}$ & .124 & $.19^{* * *}$ & .039 & $.17^{* * *}$ & .051 \\
\hline Intrinsic Motivation (B) & $.35^{* * *}$ & & $.09^{*}$ & & $-.15^{* * *}$ & \\
\hline \multicolumn{7}{|l|}{ Step Two } \\
\hline Challenge Stress $\left(\mathrm{A}_{1}\right)$ & $.10^{*}$ & .000 & $.20^{* * *}$ & .002 & $.16^{* * *}$ & .001 \\
\hline Intrinsic Motivation (B) & $.35^{* * *}$ & & $.09^{*}$ & & $-.15^{* * *}$ & \\
\hline $\mathrm{A}_{1} \mathrm{X} \mathrm{B}$ & .01 & & -.01 & & .05 & \\
\hline
\end{tabular}

Note. $* p<.05 * * p<.01 * * * p<.001$

Table 7. Moderated Regression for Intrinsic Motivation, Hindrance Stress, and Coping

Problem-Focused Emotion-Focused Maladaptive




\begin{tabular}{|c|c|c|c|c|c|c|}
\hline & $\beta$ & $\Delta \mathrm{R}^{2}$ & $\beta$ & $\Delta \mathrm{R}^{2}$ & $\beta$ & $\Delta \mathrm{R}^{2}$ \\
\hline \multicolumn{7}{|l|}{ Step One } \\
\hline Hindrance Stress $\left(\mathrm{A}_{2}\right)$ & .07 & .119 & $.11^{* *}$ & .018 & $.26^{* * *}$ & .095 \\
\hline Intrinsic Motivation (B) & $.35^{* * *}$ & & .08 & & $-.14^{* *}$ & \\
\hline \multicolumn{7}{|l|}{ Step Two } \\
\hline Hindrance Stress $\left(\mathrm{A}_{2}\right)$ & .07 & .001 & $.12^{* *}$ & .001 & $.26^{* * *}$ & .001 \\
\hline Intrinsic Motivation (B) & $.34^{* * *}$ & & $.09^{*}$ & & $-.14^{* *}$ & \\
\hline $\mathrm{A}_{2} \mathrm{X} \mathrm{B}$ & .02 & & -.03 & & .03 & \\
\hline
\end{tabular}

Note. $* p<.05 * * p<.01 * * * p<.001$

Table 8. Moderated Regression for Problem-Focused Coping, Challenge Stress, and Performance 


\begin{tabular}{|c|c|c|c|c|}
\hline & & \multirow[b]{2}{*}{$\beta$} & \multirow{2}{*}{$\Delta \mathrm{R}^{2}$} \\
\hline & $\beta$ & $\Delta \mathrm{R}^{2}$ & & \\
\hline \multicolumn{5}{|l|}{ Step One } \\
\hline Problem-Focused (A) & $.28^{* * *}$ & .052 & .05 & .003 \\
\hline Challenge Stress $\left(\mathrm{B}_{1}\right)$ & .05 & & .05 & \\
\hline \multicolumn{5}{|l|}{ Step Two } \\
\hline Problem-Focused (A) & $.28^{* * *}$ & .000 & .11 & .020 \\
\hline Challenge Stress $\left(\mathrm{B}_{1}\right)$ & .05 & & .04 & \\
\hline $\mathrm{AX} \mathrm{B}{ }_{1}$ & -.01 & & -.32 & \\
\hline
\end{tabular}

Note. $* p<.05 * * p<.01 * * * p<.001$ 


\begin{tabular}{|c|c|c|c|c|}
\hline & \multicolumn{2}{|c|}{ School Performance } & \multicolumn{2}{|c|}{ GPA } \\
\hline & $\beta$ & $\Delta \mathrm{R}^{2}$ & $\beta$ & $\Delta \mathrm{R}^{2}$ \\
\hline \multicolumn{5}{|l|}{ Step One } \\
\hline Problem-Focused (A) & $0.29^{* * *}$ & 0.046 & 0.06 & 0.006 \\
\hline Hindrance Stress $\left(\mathrm{B}_{2}\right)$ & 0.00 & & -0.08 & \\
\hline \multicolumn{5}{|l|}{ Step Two } \\
\hline Problem-Focused (A) & $.29^{* * *}$ & 0.001 & 0.07 & 0.000 \\
\hline Hindrance Stress $\left(\mathrm{B}_{2}\right)$ & 0.00 & & -0.08 & \\
\hline $\mathrm{AX} \mathrm{B} \mathrm{B}_{2}$ & 0.03 & & -0.04 & \\
\hline
\end{tabular}

Note. $* p<.05 * * p<.01 * * * p<.001$

Table 10. Moderated Regression for Emotion-Focused Coping, Challenge Stress, and Performance 


\begin{tabular}{|c|c|c|c|c|}
\hline & \multicolumn{2}{|c|}{ School Performance } & \multicolumn{2}{|c|}{ GPA } \\
\hline & $\beta$ & $\Delta \mathrm{R}^{2}$ & $\beta$ & $\Delta \mathrm{R}^{2}$ \\
\hline \multicolumn{5}{|l|}{ Step One } \\
\hline Emotion-Focused (A) & 0.06 & 0.013 & $.23^{*}$ & 0.027 \\
\hline Challenge Stress $\left(\mathrm{B}_{1}\right)$ & .05 & & 0.02 & \\
\hline \multicolumn{5}{|l|}{ Step Two } \\
\hline Emotion-Focused (A) & 0.06 & 0.002 & $.23^{*}$ & 0.000 \\
\hline Challenge Stress $\left(\mathrm{B}_{1}\right)$ & 0.04 & & 0.02 & \\
\hline $\mathrm{A} X \mathrm{~B}_{1}$ & -0.04 & & -0.01 & \\
\hline
\end{tabular}

Note. $* p<.05 * * p<.01 * * * p<.001$

Table 11. Moderated Regression for Emotion-Focused Coping, Hindrance Stress, and Performance 


\begin{tabular}{|c|c|c|c|c|}
\hline & \multicolumn{2}{|c|}{ School Performance } & \multicolumn{2}{|c|}{ GPA } \\
\hline & $\beta$ & $\Delta \mathrm{R}^{2}$ & $\beta$ & $\Delta \mathrm{R}^{2}$ \\
\hline \multicolumn{5}{|l|}{ Step One } \\
\hline Emotion-Focused (A) & $-.07^{*}$ & 0.008 & 0.25 & 0.034 \\
\hline Hindrance Stress $\left(\mathrm{B}_{2}\right)$ & 0.09 & & -0.10 & \\
\hline \multicolumn{5}{|l|}{ Step Two } \\
\hline Emotion-Focused (A) & $.08^{*}$ & 0.002 & -0.27 & 0.006 \\
\hline Hindrance Stress $\left(\mathrm{B}_{2}\right)$ & 0.09 & & -0.11 & \\
\hline $\mathrm{AX} \mathrm{B}{ }_{2}$ & -0.04 & & 0.10 & \\
\hline
\end{tabular}

Note. $* p<.05 * * p<.01 * * * p<.001$

Table 12. Moderated Regression for Maladaptive Coping, Challenge Stress, and Performance 


\begin{tabular}{|c|c|c|c|c|}
\hline & \multicolumn{2}{|c|}{ School Performance } & \multicolumn{2}{|c|}{ GPA } \\
\hline & $\beta$ & $\Delta \mathrm{R}^{2}$ & $\beta$ & $\Delta \mathrm{R}^{2}$ \\
\hline \multicolumn{5}{|l|}{ Step One } \\
\hline Maladaptive (A) & $-0.22^{* * *}$ & 0.051 & 0.00 & 0.002 \\
\hline Challenge Stress $\left(\mathrm{B}_{1}\right)$ & $0.08^{* *}$ & & 0.05 & \\
\hline \multicolumn{5}{|l|}{ Step Two } \\
\hline Maladaptive (A) & $-0.23^{* * *}$ & 0.004 & -0.01 & 0.002 \\
\hline Challenge Stress $\left(\mathrm{B}_{1}\right)$ & $0.08^{* *}$ & & 0.05 & \\
\hline $\mathrm{A} X \mathrm{~B}_{1}$ & 0.07 & & 0.08 & \\
\hline
\end{tabular}

Note. ${ }^{*} p<.05 * * p<.01 * * * p<.001$

Table 13. Moderated Regression for Maladaptive Coping, Challenge Stress, and Performance 


\begin{tabular}{|c|c|c|c|c|}
\hline & \multicolumn{2}{|c|}{ School Performance } & \multicolumn{2}{|c|}{ GPA } \\
\hline & $\beta$ & $\Delta \mathrm{R}^{2}$ & $\beta$ & $\Delta \mathrm{R}^{2}$ \\
\hline \multicolumn{5}{|l|}{ Step One } \\
\hline Maladaptive (A) & $-.22^{* * *}$ & 0.051 & 0.04 & 0.006 \\
\hline Hindrance Stress $\left(B_{2}\right)$ & $0.08^{* *}$ & & -0.09 & \\
\hline \multicolumn{5}{|l|}{ Step Two } \\
\hline Maladaptive (A) & $-.23^{* * *}$ & 0.004 & 0.03 & 0.013 \\
\hline Hindrance Stress $\left(B_{2}\right)$ & $0.08^{* *}$ & & -0.07 & \\
\hline $\mathrm{A} \mathrm{X} \mathrm{B}_{2}$ & 0.07 & & 0.23 & \\
\hline
\end{tabular}

Note. $* p<.05 * * p<.01 * * * p<.001$

Table 14. Moderated Regression for Stressors, Problem-Focused Coping, and Satisfaction 


\begin{tabular}{|c|c|c|c|c|c|}
\hline & \multicolumn{2}{|c|}{ School Satisfaction } & & \multicolumn{2}{|c|}{ School Satisfaction } \\
\hline & $\beta$ & $\Delta \mathrm{R}^{2}$ & & $\beta$ & $\Delta \mathrm{R}^{2}$ \\
\hline Step One & & & Step One & & \\
\hline Problem-Focused (A) & $0.32^{* * *}$ & 0.041 & Problem-Focused (A) & $0.32^{* * *}$ & 0.057 \\
\hline Challenge Stress $\left(\mathrm{B}_{1}\right)$ & -0.04 & & Hindrance Stress $\left(\mathrm{B}_{2}\right)$ & $-0.11^{* *}$ & \\
\hline Step Two & & & Step Two & & \\
\hline Problem-Focused (A) & $-0.32^{* * *}$ & 0.002 & Problem-Focused (A) & $-.23^{* * *}$ & 0.000 \\
\hline Challenge Stress $\left(\mathrm{B}_{1}\right)$ & -0.04 & & Hindrance Stress $\left(\mathrm{B}_{2}\right)$ & $-0.11^{* *}$ & \\
\hline $\mathrm{AX} \mathrm{B} \mathrm{B}_{1}$ & -0.007 & & $\mathrm{AX} \mathrm{B} \mathrm{B}_{2}$ & 0.02 & \\
\hline
\end{tabular}

Note. ${ }^{*} p<.05 * * p<.01 * * * p<.001$

Table 15. Moderated Regression for Stressors, Emotion-Focused Coping, and Satisfaction 


\begin{tabular}{|c|c|c|c|c|c|}
\hline & \multicolumn{2}{|c|}{ School Satisfaction } & & \multicolumn{2}{|c|}{ School Satisfaction } \\
\hline & $\beta$ & $\Delta \mathrm{R}^{2}$ & & $\beta$ & $\Delta \mathrm{R}^{2}$ \\
\hline Step One & & & Step One & & \\
\hline Emotion-Focused (A) & .04 & .003 & Emotion-Focused (A) & 0.05 & 0.018 \\
\hline Challenge Stress $\left(\mathrm{B}_{1}\right)$ & -.04 & & Hindrance Stress $\left(\mathrm{B}_{2}\right)$ & $-0.11^{* *}$ & \\
\hline Step Two & & & Step Two & & \\
\hline Emotion-Focused (A) & .04 & .001 & Emotion-Focused (A) & 0.05 & 0.000 \\
\hline Challenge Stress $\left(\mathrm{B}_{1}\right)$ & -.04 & & Hindrance Stress $\left(\mathrm{B}_{2}\right)$ & -0.08 & \\
\hline $\mathrm{AX} \mathrm{B} \mathrm{B}_{1}$ & .02 & & $\mathrm{~A} \mathrm{X} \mathrm{B}{ }_{2}$ & -0.01 & \\
\hline
\end{tabular}

Note. ${ }^{*} p<.05 * * p<.01 * * * p<.001$

Table 16. Moderated Regression Summary for Stressors, Maladaptive Coping, and Satisfaction 


\begin{tabular}{|c|c|c|c|c|c|}
\hline & \multicolumn{2}{|c|}{ School Satisfaction } & & \multicolumn{2}{|c|}{ School Satisfaction } \\
\hline & $\beta$ & $\Delta \mathrm{R}^{2}$ & & $\beta$ & $\Delta \mathrm{R}^{2}$ \\
\hline Step One & & & Step One & & \\
\hline Maladaptive (A) & $-0.17^{* *}$ & 0.020 & Maladaptive (A) & $-0.14^{*}$ & 0.025 \\
\hline Challenge Stress $\left(B_{1}\right)$ & -0.01 & & Hindrance Stress $\left(\mathrm{B}_{2}\right)$ & $-0.08^{*}$ & \\
\hline Step Two & & & Step Two & & \\
\hline Maladaptive (A) & $-0.17^{* *}$ & 0.001 & Maladaptive (A) & $-0.13^{* *}$ & 0.001 \\
\hline Challenge Stress $\left(B_{1}\right)$ & -0.01 & & Hindrance Stress $\left(B_{2}\right)$ & $-0.08^{*}$ & \\
\hline $\mathrm{A} X \mathrm{~B}_{1}$ & -0.04 & & $\mathrm{~A} X \mathrm{~B}_{2}$ & -0.08 & \\
\hline
\end{tabular}

Note. ${ }^{*} p<.05 * * p<.01 * * * p<.001$

Table 17. Moderated Regression for CSE Self-Esteem, Stressors, and Coping 


\begin{tabular}{|c|c|c|c|c|c|}
\hline & \multicolumn{2}{|c|}{ Problem-Focused } & & \multicolumn{2}{|c|}{ Problem-Focusec } \\
\hline & $\beta$ & $\Delta \mathrm{R}^{2}$ & & $\beta$ & $\Delta \mathrm{R}^{2}$ \\
\hline \multicolumn{6}{|l|}{ Step One } \\
\hline Challenge Stress $\left(A_{1}\right)$ & $.11^{* *}$ & .058 & Hindrance Stress $\left(\mathrm{A}_{2}\right)$ & $.14^{* *}$ & .059 \\
\hline CSE - Self-Esteem $\left(B_{1}\right)$ & $.24^{* * *}$ & & CSE - Self-Esteem $\left(B_{1}\right)$ & $.27^{* * *}$ & \\
\hline \multicolumn{6}{|l|}{ Step Two } \\
\hline Challenge Stress $\left(A_{1}\right)$ & $.12^{* *}$ & .009 & Hindrance Stress $\left(\mathrm{A}_{2}\right)$ & $.14^{* *}$ & .014 \\
\hline CSE - Self-Esteem $\left(B_{1}\right)$ & $.25^{* * *}$ & & CSE - Self-Esteem $\left(B_{1}\right)$ & $.28^{* * *}$ & \\
\hline $\mathrm{A}_{1} \mathrm{X} \mathrm{B}_{1}$ & $-.10^{*}$ & & $\mathrm{~A}_{2} \mathrm{X} \mathrm{B}_{1}$ & $-.12^{* *}$ & \\
\hline
\end{tabular}

Note. $* p<.05 * * p<.01 * * * p<.001$

Table 18. Moderated Regression Summary for CSE Neuroticism, Stressors, and Coping 


\begin{tabular}{|c|c|c|c|c|c|}
\hline & \multicolumn{2}{|c|}{ Problem-Focused } & & \multicolumn{2}{|c|}{ Problem-Focused } \\
\hline & $\beta$ & $\Delta \mathrm{R}^{2}$ & & $\beta$ & $\Delta \mathrm{R}^{2}$ \\
\hline \multicolumn{6}{|l|}{ Step One } \\
\hline Challenge Stress $\left(\mathrm{A}_{1}\right)$ & $.11^{* *}$ & .020 & Hindrance Stress $\left(\mathrm{A}_{2}\right)$ & $.12^{*}$ & .017 \\
\hline CSES - Neuroticism $\left(B_{2}\right)$ & $.14^{* *}$ & & CSE - Neuroticism $\left(B_{2}\right)$ & $.16^{* *}$ & \\
\hline Step Two & & .008 & & & \\
\hline Challenge Stress $\left(\mathrm{A}_{1}\right)$ & $.13^{* *}$ & & Hindrance Stress $\left(\mathrm{A}_{2}\right)$ & $.11^{*}$ & .013 \\
\hline CSE - Neuroticism $\left(B_{2}\right)$ & $.15^{* *}$ & & CSE - Neuroticism $\left(B_{2}\right)$ & $.17^{* *}$ & \\
\hline $\mathrm{A}_{1} \mathrm{X} \mathrm{B}_{2}$ & $-.09 *$ & & $\mathrm{~A}_{2} \mathrm{X} \mathrm{B}$ & $-.13^{* *}$ & \\
\hline
\end{tabular}

Note. $* p<.05 * * p<.01 * * * p<.001$

Table 19. Moderated Regression Summary for CSE Self-Efficacy, Stressors, and Coping 


\begin{tabular}{|c|c|c|c|c|c|}
\hline & \multicolumn{2}{|c|}{ Problem-Focused } & & \multicolumn{2}{|c|}{ Problem-Focused } \\
\hline & $\beta$ & $\Delta \mathrm{R}^{2}$ & & $\beta$ & $\Delta \mathrm{R}^{2}$ \\
\hline \multicolumn{6}{|l|}{ Step One } \\
\hline Challenge Stress $\left(A_{1}\right)$ & $.10^{*}$ & .008 & Hindrance Stress $\left(\mathrm{A}_{2}\right)$ & .09 & .006 \\
\hline CSE - Self-Efficacy $\left(\mathrm{B}_{3}\right)$ & $.10^{*}$ & & CSE -Self-Efficacy $\left(B_{3}\right)$ & $.10^{*}$ & \\
\hline \multicolumn{6}{|l|}{ Step Two } \\
\hline Challenge Stress $\left(A_{1}\right)$ & $.11^{*}$ & .003 & Hindrance Stress $\left(\mathrm{A}_{2}\right)$ & .08 & .007 \\
\hline CSE - Self-Efficacy $\left(\mathrm{B}_{3}\right)$ & $.10^{*}$ & & CSE -Self-Efficacy $\left(\mathrm{B}_{3}\right)$ & $.10^{*}$ & \\
\hline $\mathrm{A}_{1} \mathrm{X} \mathrm{B}_{3}$ & -.07 & & $\mathrm{~A}_{2} \mathrm{X} \mathrm{B}_{3}$ & $-.09^{*}$ & \\
\hline
\end{tabular}

Note. ${ }^{*} p<.05 * * p<.01 * * * p<.001$

Table 20. Moderated Regression Summary for CSE Locus of Control, Stressors, and Coping 


\begin{tabular}{|c|c|c|c|c|c|}
\hline & \multicolumn{2}{|c|}{ Problem-Focused } & & \multicolumn{2}{|c|}{ Problem-Focused } \\
\hline & $\beta$ & $\Delta \mathrm{R}^{2}$ & & $\beta$ & $\Delta \mathrm{R}^{2}$ \\
\hline \multicolumn{6}{|l|}{ Step One } \\
\hline Challenge Stress $\left(A_{1}\right)$ & $.11^{*}$ & .026 & Hindrance Stress $\left(\mathrm{A}_{2}\right)$ & $.11^{*}$ & .026 \\
\hline CSES - LOC $\left(B_{4}\right)$ & $.17^{* * *}$ & & $\mathrm{CSE}-\mathrm{LOC}\left(\mathrm{B}_{4}\right)$ & $.18^{* * *}$ & \\
\hline Step Two & & .006 & & & \\
\hline Challenge Stress $\left(A_{1}\right)$ & $.12^{* *}$ & & Hindrance Stress $\left(\mathrm{A}_{2}\right)$ & $.11^{*}$ & .014 \\
\hline $\mathrm{CSE}-\mathrm{LOC}\left(\mathrm{B}_{4}\right)$ & $.18^{* * *}$ & & $\mathrm{CSE}-\mathrm{LOC}\left(\mathrm{B}_{4}\right)$ & $.20^{* * *}$ & \\
\hline $\mathrm{A}_{1} \times \mathrm{B}_{4}$ & $-.10^{*}$ & & $\mathrm{~A}_{2} \mathrm{X} \mathrm{B}_{4}$ & $-.13^{* *}$ & \\
\hline
\end{tabular}

Note. ${ }^{*} p<.05 * * p<.01 * * * p<.001$, LOC $=$ Locus of Control

Table 21. Correlations, Means, Standard Deviations, and Reliabilities for Employees 


\begin{tabular}{|c|c|c|c|c|c|c|c|c|c|c|c|c|}
\hline Variable & M & SD & 1 & 2 & 3 & 4 & 5 & 6 & 7 & 8 & 9 & 10 \\
\hline 1. Challenge Stress & 3.23 & 1.06 & $(.95)$ & & & & & & & & & \\
\hline 2. Hindrance Stress & 2.24 & .97 & $.42^{*}$ & $(.85)$ & & & & & & & & \\
\hline 3. CSES & 5.41 & .82 & -.05 & -.28 & $(.83)$ & & & & & & & \\
\hline 4. Intrinsic Motivation & 2.95 & .56 & .17 & -.26 & .03 & $(.91)$ & & & & & & \\
\hline 5. Extrinsic Motivation & 3.09 & .56 & -.12 & -.14 & .18 & -.15 & $(.80)$ & & & & & \\
\hline 6. Problem-Focused & 2.98 & .45 & -.08 & .15 & .22 & -.07 & $.45^{*}$ & $(.89)$ & & & & \\
\hline 7. Emotion-Focused & 2.49 & .80 & .08 & .25 & .06 & .21 & $.34^{\dagger}$ & $.44^{*}$ & $(.92)$ & & & \\
\hline 8. Maladaptive & 1.73 & .82 & .04 & -.03 & -.17 & .26 & .22 & .27 & $.66^{* * *}$ & $(.93)$ & & \\
\hline 9. Satisfaction & 3.77 & .90 & -.15 & $-.40^{*}$ & .25 & -.19 & .04 & .16 & $-.34^{\dagger}$ & -.22 & $(.82)$ & \\
\hline 10. Performance & 6.47 & .58 & .04 & -.17 & .15 & -.19 & -.04 & .25 & $-.37^{\dagger}$ & -.23 & $.54^{* *}$ & $(.86)$ \\
\hline
\end{tabular}

Note. Alpha reliabilities on the diagonal. $\uparrow \mathrm{p}<.10 * \mathrm{p}<.05 * * \mathrm{p}<.01 * * * \mathrm{p}<.001$

APPENDIX B - Figures 
Figure 1. Challenge Transactional Cognitive Appraisal Model of Stress

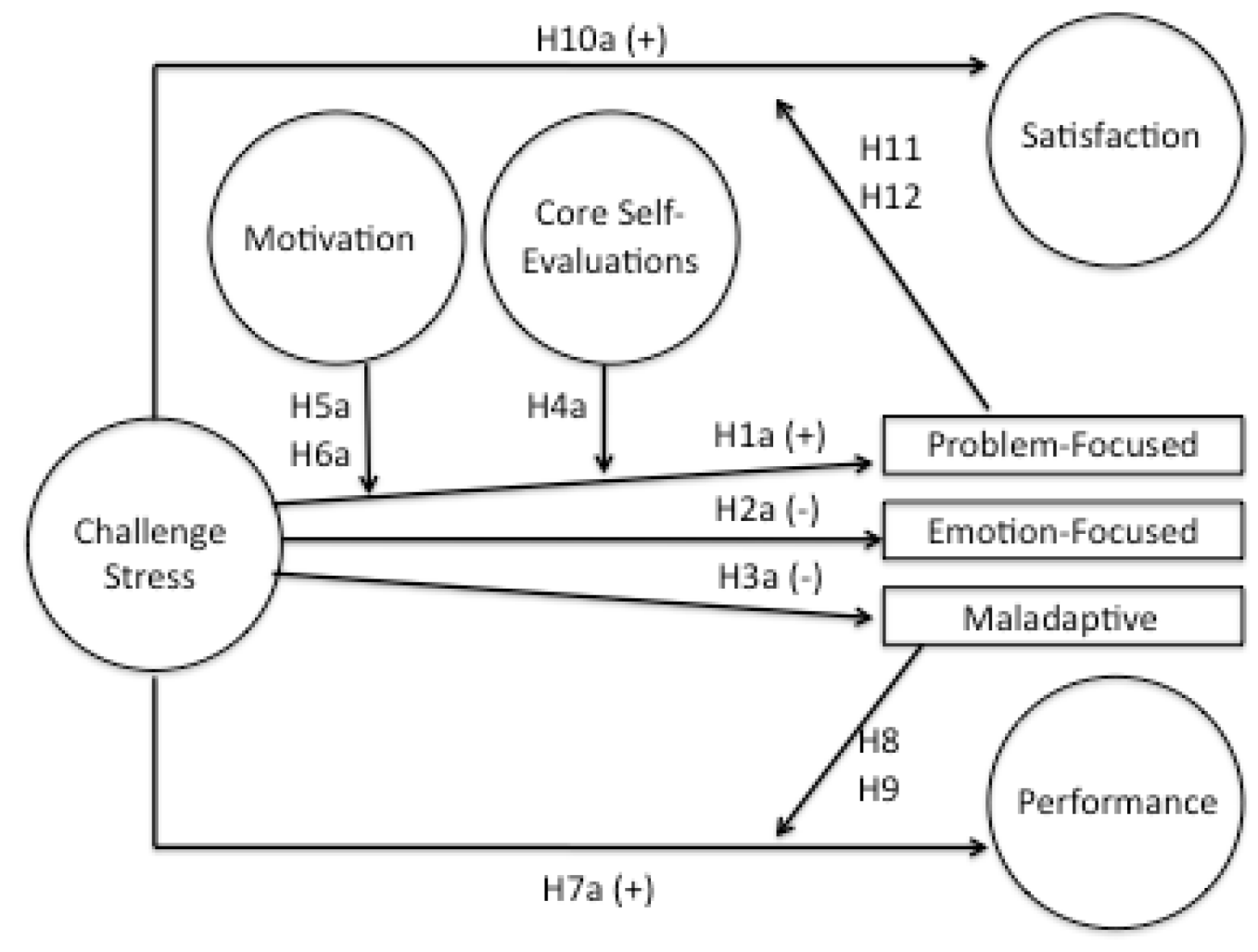

Figure 2. Hindrance Transactional Cognititive Appraisal Model of Stress 




Figure 3. Interaction Graph of Challenge Stressors, Problem-Focused Coping, and CSE 


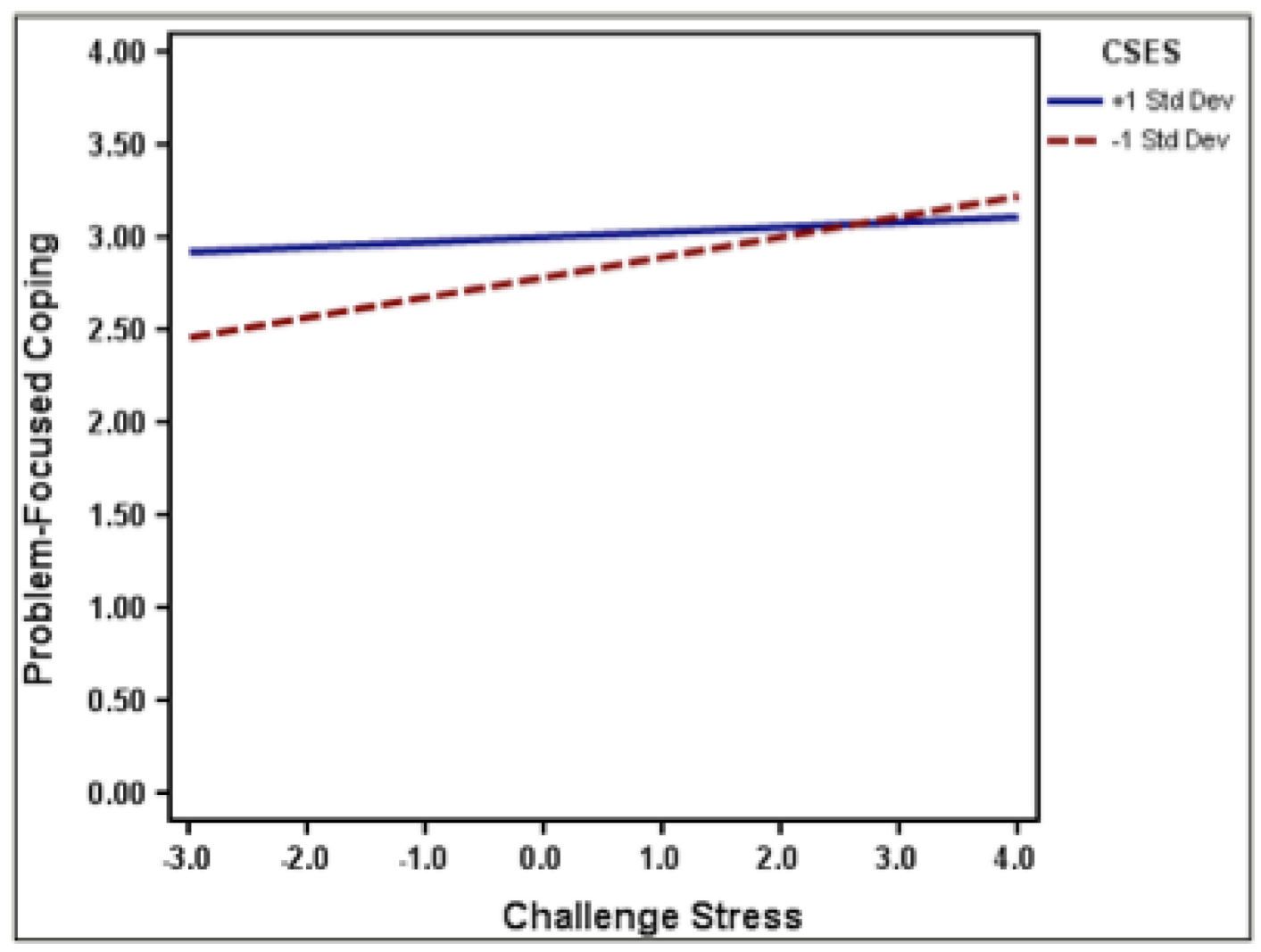

Figure 4. Interaction Graph of Hindrance Stressors, Problem-Focused Coping, and CSE 


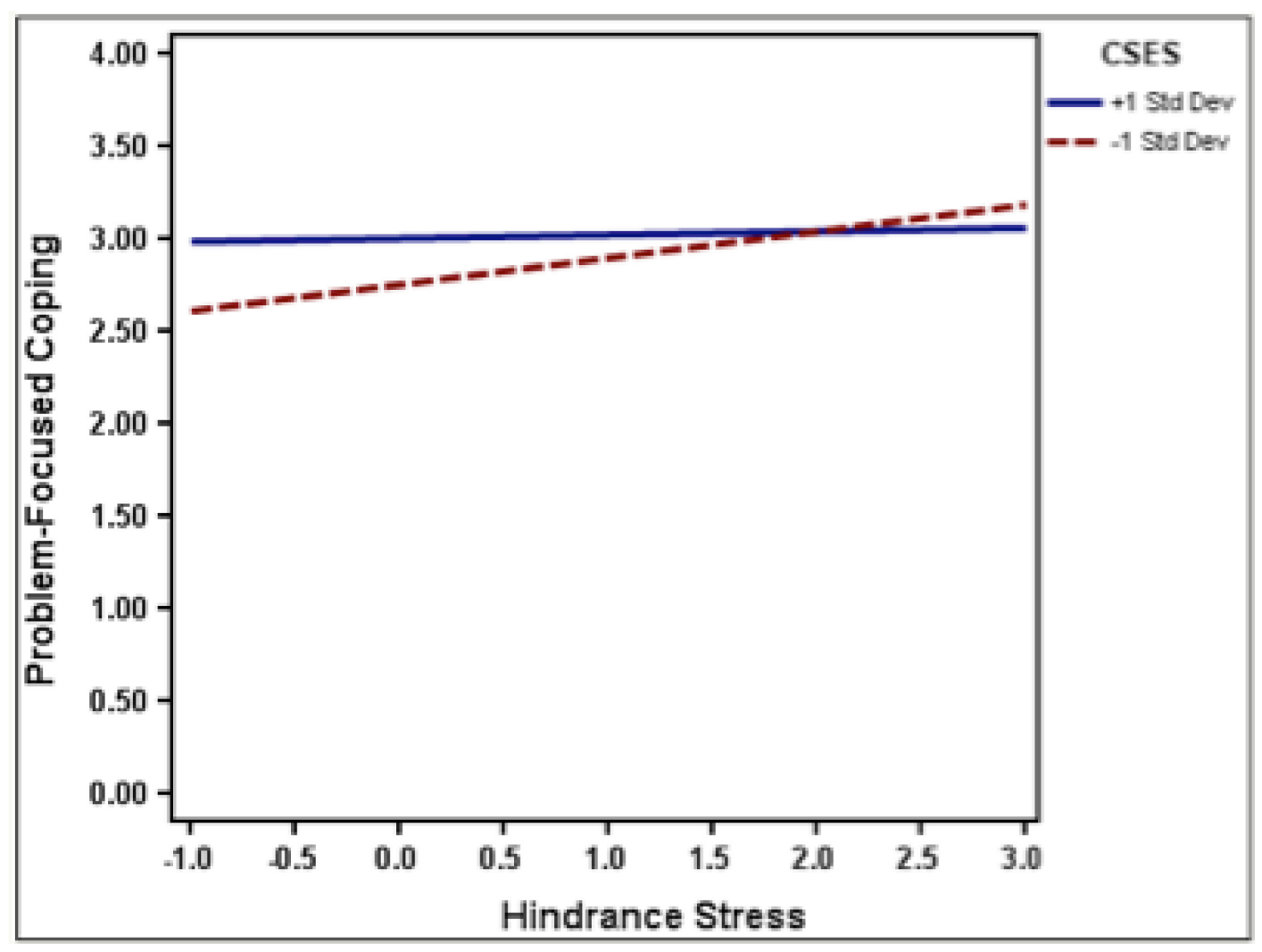

Figure 5. Interaction Graph of Challenge Stressors, Problem-Focused Coping and Self-Esteem (CSES) 


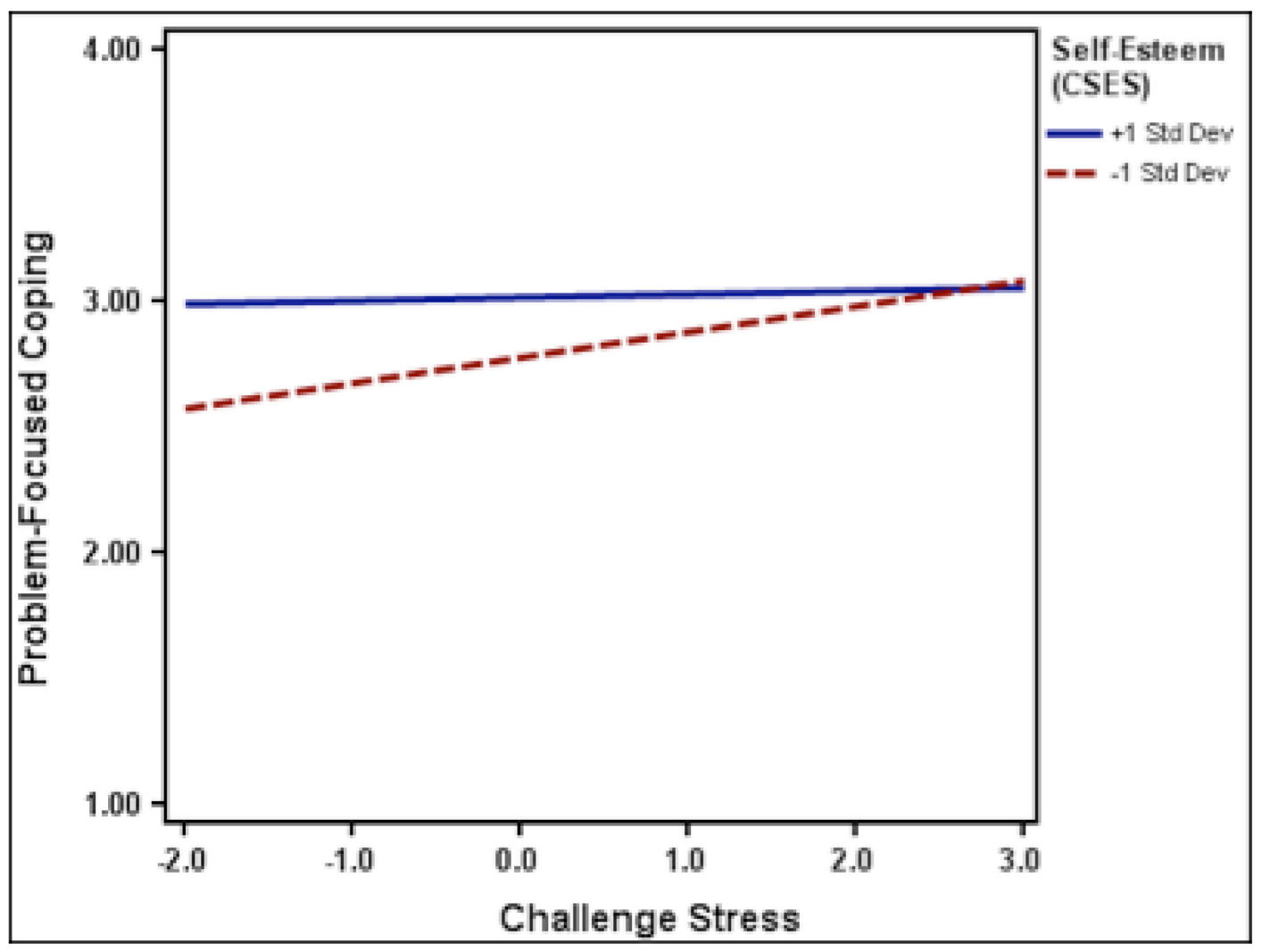

Figure 6. Interaction Graph of Challenge Stressors, Problem-Focused Coping and Neuroticism (CSES) 


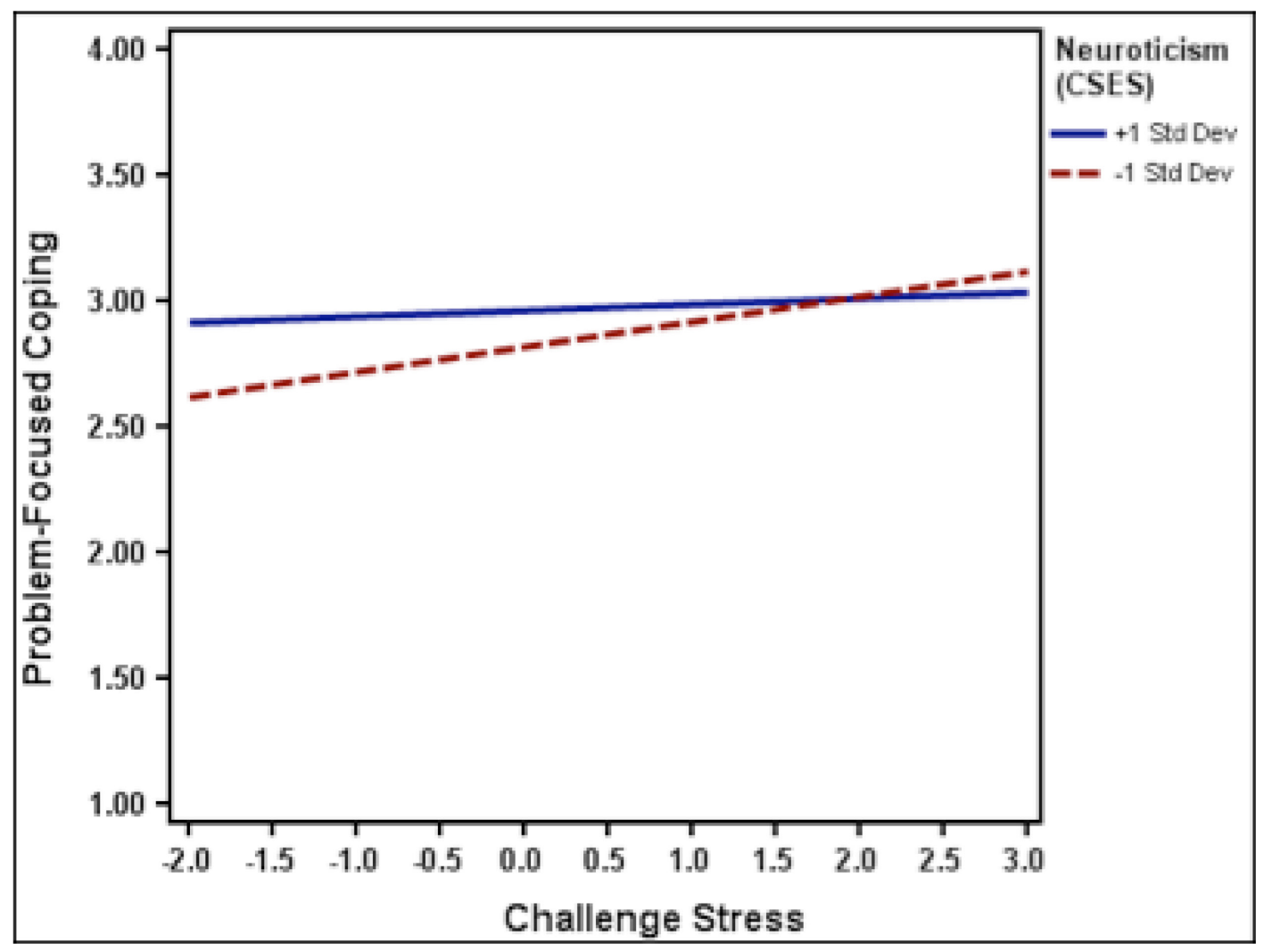

Figure 7. Interaction Graph of Challenge Stressors, Problem-Focused Coping and Self-Efficacy (CSES) 




Figure 8. Interaction Graph of Challenge Stressors, Problem-Focused Coping and Locus of Control (CSES) 


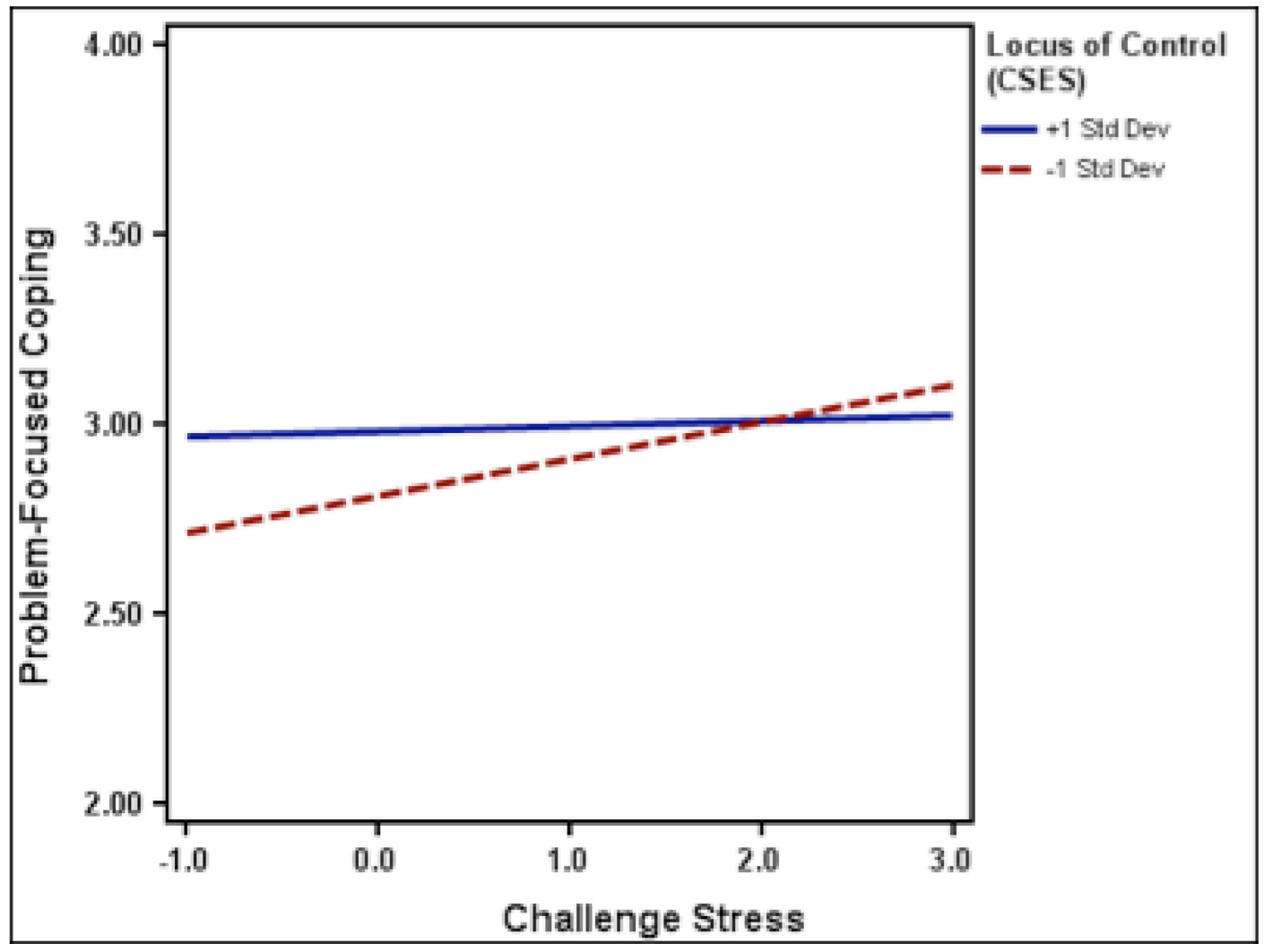

Figure 9. Interaction Graph of Hindrance Stressors, Problem-Focused Coping and Self-Esteem (CSES) 


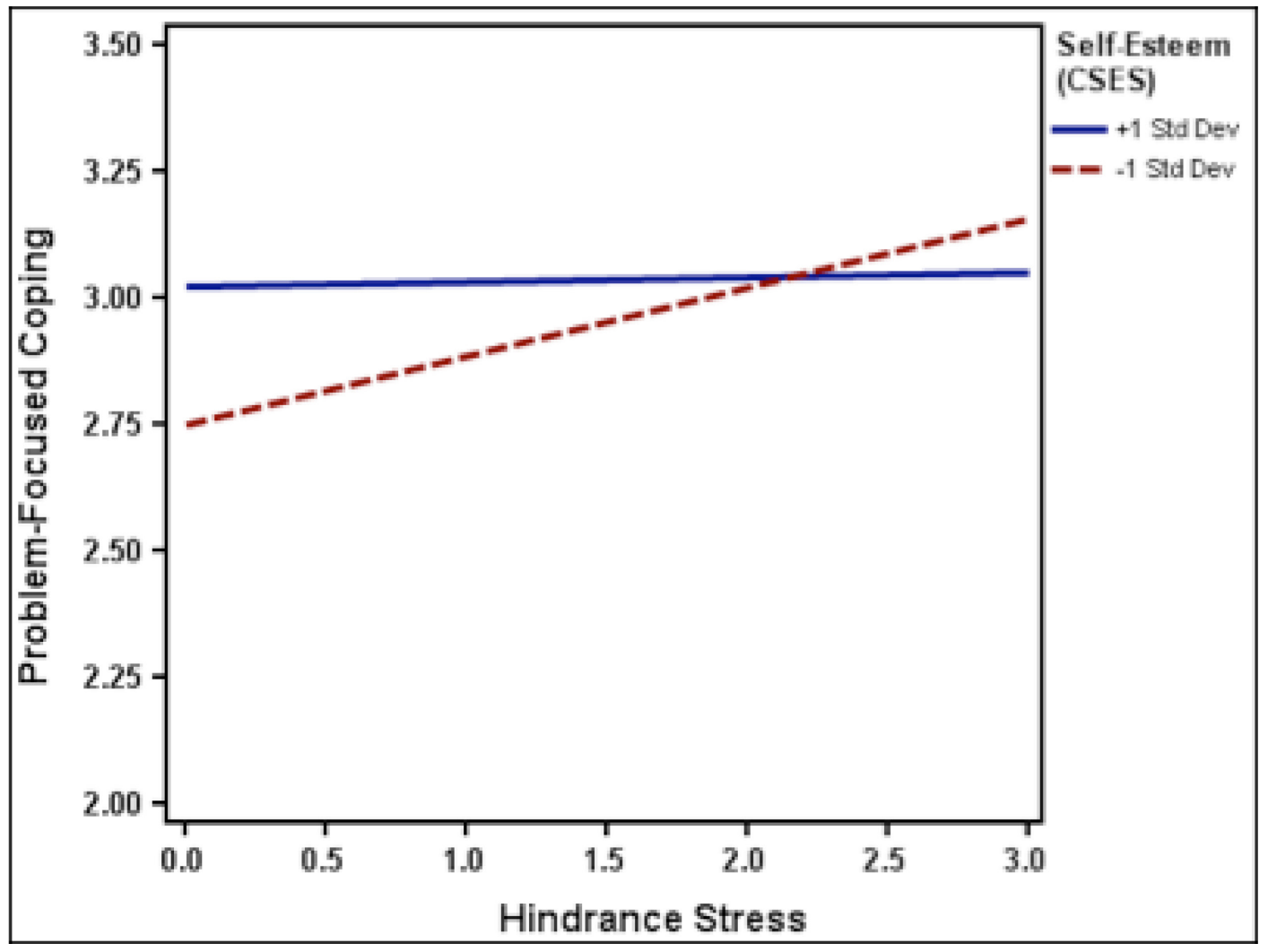

Figure 10. Interaction Graph of Hindrance Stressors, Problem-Focused Coping and Neuroticism (CSES) 




Figure 11. Interaction Graph of Hindrance Stressors, Problem-Focused Coping and Self-Efficacy (CSES) 




Figure 12. Interaction Graph of Hindrance Stressors, Problem-Focused Coping and Locus of Control (CSES) 


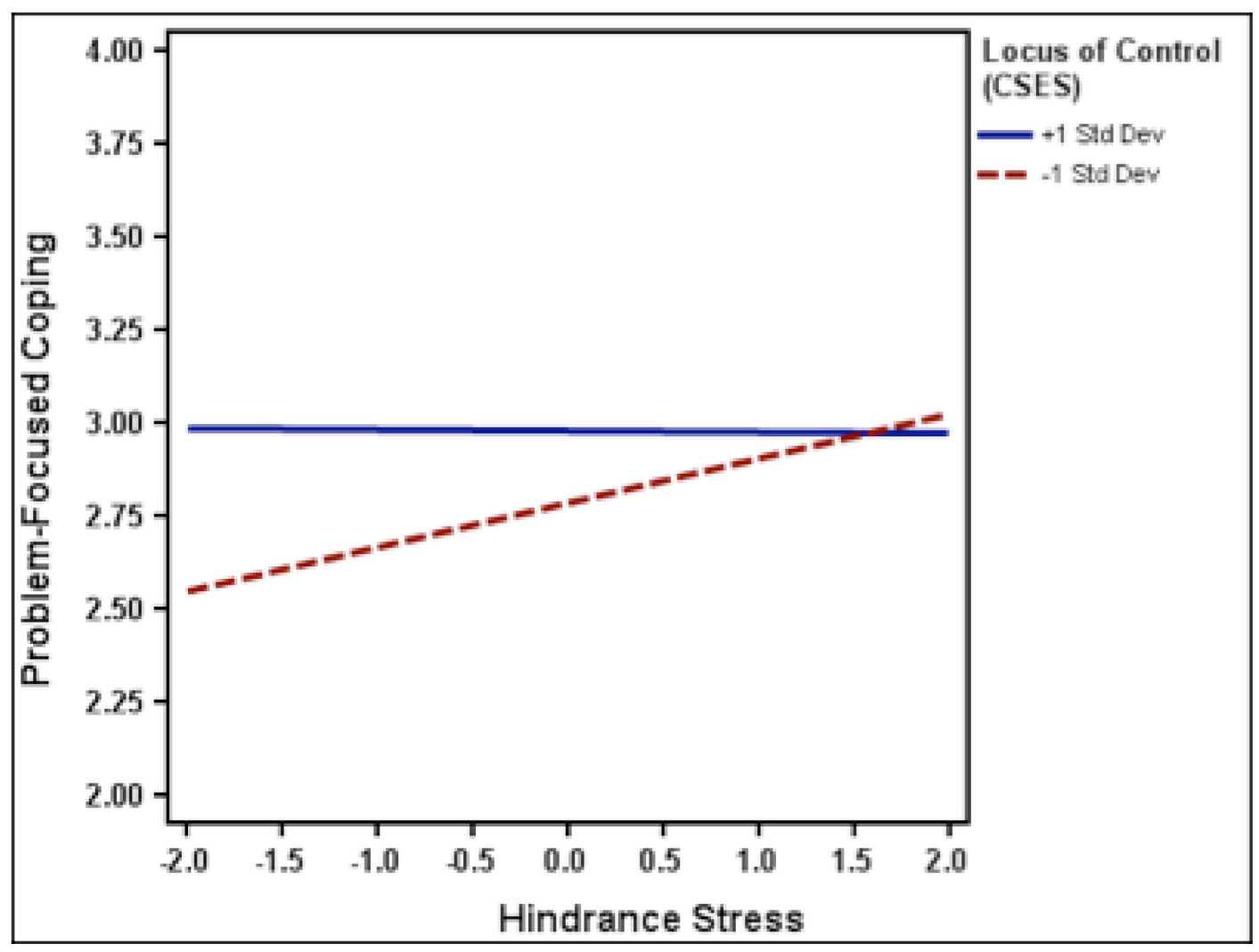

